\section{Global strategy for asthma management and prevention: GINA executive summary}

\author{
E.D. Bateman*, S.S. Hurd ${ }^{\#}$, P.J. Barnes ${ }^{\dagger}$, J. Bousquet ${ }^{+}$, J.M. Drazen ${ }^{\S}$, M. FitzGerald ${ }^{f}$, \\ P. Gibson**, K. Ohta ${ }^{\# \#}$, P. O’Byrne ${ }^{\top \uparrow}$, S.E. Pedersen ${ }^{++}$, E. Pizzichini ${ }^{\S \S}$, S.D. Sullivan ${ }^{f f}$, \\ S.E. Wenzel ${ }^{* * *}$ and H.J. Zar*
}

ABSTRACT: Asthma is a serious health problem throughout the world. During the past two decades, many scientific advances have improved our understanding of asthma and ability to manage and control it effectively. However, recommendations for asthma care need to be adapted to local conditions, resources and services. Since it was formed in 1993, the Global Initiative for Asthma, a network of individuals, organisations and public health officials, has played a leading role in disseminating information about the care of patients with asthma based on a process of continuous review of published scientific investigations. A comprehensive workshop report entitled "A Global Strategy for Asthma Management and Prevention", first published in 1995, has been widely adopted, translated and reproduced, and forms the basis for many national guidelines. The 2006 report contains important new themes. First, it asserts that "it is reasonable to expect that in most patients with asthma, control of the disease can and should be achieved and maintained," and recommends a change in approach to asthma management, with asthma control, rather than asthma severity, being the focus of treatment decisions. The importance of the patient-care giver partnership and guided self-management, along with setting goals for treatment, are also emphasised.

KEYWORDS: Asthma, chronic disease, guidelines, human

\section{CONTENTS}

Introduction 144

Methodology and summary of new recommendations

Levels of evidence

Definition and overview

Definition

Burden of asthma

Factors influencing the development and expression of asthma

Diagnosis and classification

Clinical diagnosis 146

Tests for diagnosis and monitoring 146

Diagnostic challenges and differentia

Distinguishing asthma from COPD

Classification of asthma

Asthma treatments

Asthma medications: adults

Asthma treatment: children

Asthma management and prevention
AFFILIATIONS

*University of Cape Town, Cape Town, South Africa.

\#Global Initiative for Asthma, Gaithersburg, MD,

§Harvard Medical School, Boston, $M A$,

ffUniversity of Washington, Seattle, WA, and

***University of Pittsburgh,

Pittsburgh, PA, USA.

"National Heart and Lung Institute, London, UK.

${ }^{+}$Montpellier University and INSERM

Montpellier, France.

fUniversity of British Columbia,

Vancouver, BC, and

\#\#McMaster University, Hamilton, ON, Canada.

**John Hunter Hospital, New Castle, New South Wales, Australia.

"Teikyo University School of Medicine, Tokyo, Japan.

"Kolding Hospital, Kolding, Denmark.

${ }^{\S \S}$ Universidade Federal de Santa

Catarina, Florianópolis, Brazil.

\section{CORRESPONDENCE}

E.D. Bateman, University of Cape Town Lung Institute, PO Box 34560, Groote School, 7700 Mowbray, Cape Town, South Africa.

Fax: 27214066902

E-mail: ebateman@

uctgsh1.uct.ac.za

Received:

October 222007

Accepted after revision:

October 242007

STATEMENT OF INTEREST: Statements of interest for E.D. Bateman, S.S. Hurd, P.J. Barnes, J. Bousquet, M. FitzGerald, P. Gibson, K. Ohta, P. O'Byrne, S.E. Pedersen, E. Pizzichini, S.D. Sullivan, S.E. Wenzel and H.J. Zar can be found at www.erj.ersjournals.co.uk/misc/statements.shtml 
Component 1: develop patient-doctor partnership . . . . 154

Component 2: identify and reduce exposure to risk factors 155

Component 3: assess, treat and monitor asthma . . . . 156

Component 4: managing asthma exacerbations . . . . . 160

Component 5: special considerations . . . . . . . . . . . 164

\section{INTRODUCTION}

Asthma is a serious global health problem. People of all ages throughout the world are affected by this chronic airway disorder that, when uncontrolled, can place severe limits on daily life and is sometimes fatal. The prevalence of asthma is increasing in most countries, especially among children. The burden of asthma is experienced not only in terms of healthcare costs but also as lost productivity and reduced participation in family life. During the past two decades, many scientific advances have improved our understanding of asthma and our ability to manage and control it effectively. However, the diversity of healthcare systems and variations in the availability of asthma therapies require that recommendations for asthma care be adapted to local conditions throughout the global community. Public health officials require information about the costs of asthma care and education on methods to develop asthma care services and programmes responsive to the particular needs and circumstances within their countries.

In 1993, the Global Initiative for Asthma (GINA) was implemented to develop a network of individuals, organisations and public health officials for the dissemination of information regarding the care of patients with asthma, while at the same time assuring a mechanism to incorporate the results of scientific investigations into asthma care. In 1995, in collaboration with the National Heart, Lung, and Blood Institute of the USA and the World Health Organization (WHO), GINA developed a Global Strategy for Asthma Management and Prevention; this 1995 report was revised in 2002 [1]. Publications based on the Global Strategy for Asthma Management and Prevention have been translated into many different languages to promote international collaboration and dissemination of information. An annual World Asthma Day, initiated in 1991, is gaining increasing attention each year in raising awareness about asthma.

The 2002 GINA report stated: "it is reasonable to expect that in most patients with asthma, control of the disease can and should be achieved and maintained" [1]. To meet this challenge, the 2006 report not only incorporates updated scientific information but also describes a development of this theme and a change in approach to asthma management, with asthma control, rather than asthma severity, being the focus of treatment decisions [2]. The control-driven approach proposed involves an iterative cycle of assessment, treatment and adjustments to maintain asthma control, with control as the target. This paradigm shift for asthma care reflects progress in pharmacological care of patients. Many asthma patients are receiving, or have received, some asthma medications. The role of the healthcare professional is to establish each patient's current level of treatment and control, then to adjust treatment to gain and maintain control. The importance of the patientcare giver partnership and guided self-management, along with setting goals for treatment, are further central themes of the revision.
Implementation of asthma guidelines in health systems 165

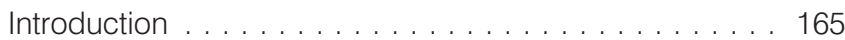

Guideline implementation strategies . . . . . . . . . . . 165

GINA dissemination and implementation resources . . . 166

References ........................ 166

While early diagnosis of asthma and implementation of appropriate therapy significantly reduces the socioeconomic impact of asthma and enhances patients' quality of life, medications continue to be the major component of the cost of asthma treatment and the pricing of asthma medications continues to be a topic for urgent action. A large segment of the world's population lives in areas with inadequate medical facilities and meagre financial resources, particularly for the management of chronic diseases. The GINA Executive Committee recognises that "fixed" international guidelines and "rigid" scientific protocols will not work in many locations. Therefore, the recommendations found in the present report must be adapted to fit local practices and the availability of healthcare resources.

\section{Methodology and summary of new recommendations}

Since the 2001 GINA report, the Science Committee has continued its programme of keeping the GINA documents current by reviewing published research, evaluating the impact of this research on the management and prevention of asthma and has posted yearly updates of these documents on the GINA website [3]. The 2006 GINA report is a complete revision, commenced in January 2005 and completed in November 2006. Several reviewers were invited to submit comments. The report recommends the following.

1) An overall concept for asthma management is presented and oriented around the focus on asthma control. Achieving and maintaining asthma control is emphasised as the goal of asthma treatment.

2) Classification of asthma by level of control is recommended: controlled, partly controlled or uncontrolled.

3) The previous classification of asthma by severity into intermittent, mild persistent, moderate persistent and severe persistent is recommended only for research purposes.

4) Effective management of asthma requires the development of a partnership between the person with asthma and his or her healthcare professional(s) (and parents/caregivers, in the case of children with asthma).

5) Treatment options are organised into five "steps" reflecting increasing intensity of treatment (dosages and/or number of medications) required to achieve control. At all steps, a reliever medication should be provided for as-needed use. At steps $2-5$, a variety of controller medications are available.

6) If asthma is not controlled on the current treatment regimen, treatment should be stepped up until control is achieved. When control is maintained, treatment can be stepped down in order to find the lowest step and dose of treatment that maintains control.

7) Although each component contains management advice for all age categories where these are considered relevant, special 
challenges must be taken into account in making recommendations for managing asthma in children in the first 5 yrs of life.

8) A chapter has been added on implementation of asthma guidelines in health systems, which details the process and economics of guideline implementation.

\section{Levels of evidence}

Levels of evidence are assigned to management recommendations where appropriate in Section 3: Components of Asthma Management with a system used in previous GINA reports (table 1). Throughout the present report, evidence levels are indicated in parentheses after the relevant statement, e.g. (Evidence A).

\section{DEFINITION AND OVERVIEW}

\section{Definition}

Asthma is a disorder defined by its clinical, physiological and pathological characteristics as follows. "Asthma is a chronic inflammatory disorder of the airways in which many cells and cellular elements play a role. The chronic inflammation is associated with airway hyperresponsiveness that leads to recurrent episodes of wheezing, breathlessness, chest tightness, and coughing, particularly at night or in the early morning. These episodes are usually associated with widespread, but variable, airflow obstruction within the lung that is often reversible either spontaneously or with treatment" [2].

Since its pathogenesis is not clear, this definition is descriptive and inclusive of different phenotypes that are being increasingly recognised both on clinical grounds, including responsiveness to treatment, and on the basis of genetic and causative pathological features.

There is now good evidence that the clinical manifestations of asthma (symptoms, sleep disturbances, limitations of daily activity, impairment of lung function and use of rescue medications) can, in a large proportion of patients, be controlled with appropriate treatment. When asthma is controlled, there should be no more than occasional recurrence of symptoms and severe exacerbations should be rare [4].

\section{Burden of asthma}

Worldwide, an estimated 300 million people are affected by asthma $[5,6]$. Based on the application of standardised methods to the measurement of the prevalence of asthma and wheezing illness in children [5] and adults [7], it appears that the global prevalence of asthma ranges $1-18 \%$ of the population in different countries. Its prevalence has been increasing in some countries [8,9] but has stabilised or even begun to decline in others $[10,11]$. The $\mathrm{WHO}$ has estimated that 15 million disability-adjusted life-yrs are lost annually due to asthma, representing 1\% of the total global disease burden [12]. Annual worldwide deaths from asthma have been estimated at 250,000 and mortality does not appear to correlate well with prevalence. There are insufficient data to fully explain the variations in prevalence within and between populations. Although from the perspective of both the patient and society the cost to control asthma seems high, the cost of not treating asthma correctly is even higher [13-15]. There is every reason to believe that the substantial global burden of asthma can be dramatically reduced through efforts by individuals, their healthcare providers, healthcare organisations, and local and national governments to improve asthma control.

Detailed reference information about the burden of asthma can be found in the Global Burden of Asthma Report [5].

\section{Factors influencing the development and expression of asthma}

Factors that influence the risk of asthma can be divided into those that cause the development of asthma and those that trigger asthma symptoms; some do both.

The former include host factors (which are primarily genetic) and the latter are usually environmental factors. However, the mechanisms whereby these factors influence the development and expression of asthma are complex and interactive. For example, genes probably interact both with other genes and

\section{TABLE 1 Description of levels of evidence}

\begin{tabular}{|c|c|c|}
\hline A & $\begin{array}{c}\text { RCTs } \\
\text { Rich body of data }\end{array}$ & $\begin{array}{l}\text { Evidence is from end-points of well-designed RCTs that provide a consistent pattern of findings in the } \\
\text { population for which the recommendation is made. Evidence Category A requires substantial } \\
\text { numbers of studies involving substantial numbers of participants. }\end{array}$ \\
\hline B & $\begin{array}{c}\text { RCTs } \\
\text { Limited body of data }\end{array}$ & $\begin{array}{l}\text { Evidence is from end-points of intervention studies that include only a limited number of patients, post } \\
\text { hoc or subgroup analysis of RCTs, or meta-analysis of RCTs. In general, Evidence Category B pertains } \\
\text { when few randomised trials exist, they are small in size, they were undertaken in a population that } \\
\text { differs from the target population of the recommendation, or the results are somewhat inconsistent. }\end{array}$ \\
\hline C & $\begin{array}{l}\text { Nonrandomised trials } \\
\text { Observational studies }\end{array}$ & Evidence is from outcomes of uncontrolled or nonrandomised trials or from observational studies. \\
\hline D & Panel consensus judgment & $\begin{array}{l}\text { This Evidence Category is used only in cases where the provision of some guidance was deemed } \\
\text { valuable but the clinical literature addressing the subject was insufficient to justify placement in one } \\
\text { of the other categories. The Panel Consensus is based on clinical experience or knowledge that } \\
\text { does not meet the aforementioned criteria. }\end{array}$ \\
\hline
\end{tabular}


with environmental factors to determine asthma susceptibility $[16,17]$. In addition, developmental aspects, such as the maturation of the immune response and the timing of infectious exposures during the first years of life, are emerging as important factors that modify the risk of asthma in the genetically susceptible person. The apparent racial and ethnic differences in the prevalence of asthma reflect underlying genetic variances with a significant overlay of socioeconomic and environmental factors. The higher prevalence of asthma in developed than in developing nations, and in affluent compared with poor populations in developing nations, is likely to reflect lifestyle differences, such as exposure to allergens, access to healthcare, etc.

Occupational sensitisers account, in part, for the higher prevalence of asthma in urban populations and are risk factors for both developing asthma and asthma symptoms. In contrast, air pollution and some allergens cause symptoms but have not been clearly linked to the development of asthma.

The interaction between atopy and viral infections is complex [18]. The atopic state influences lower airway responses to viral infections and viral infections can influence the development of allergic sensitisation, especially when individuals are exposed simultaneously to both. Exposure to tobacco smoke has several effects in patients at risk of asthma. It increases the risk of allergic sensitisation, is associated with accelerated decline of lung function in people with asthma, increases asthma severity, renders patients less responsive to treatment with inhaled [19, 20] and systemic [21] glucocorticosteroids, and reduces the likelihood of asthma being controlled [22].

\section{DIAGNOSIS AND CLASSIFICATION \\ Clinical diagnosis}

Medical history

A clinical diagnosis of asthma is suggested by symptoms such as episodic breathlessness, wheezing, cough and chest tightness [23]. Episodic symptoms after an incidental allergen exposure, seasonal variability of symptoms and a positive family history of asthma and atopic disease are also helpful diagnostic guides. The patterns of these symptoms that strongly suggest an asthma diagnosis are: variability; precipitation by nonspecific irritants, such as smoke, fumes, strong smells or exercise; worsening at night; and responding to appropriate asthma therapy.

In some sensitised individuals, asthma may be exacerbated by seasonal increases in specific aeroallergens (Alternaria and birch, grass and ragweed pollens) [24]. Cough-variant asthma (patients have chronic cough as their principal, if not only, symptom) is particularly common in children and is often more problematic at night; evaluations during the day can be normal [25]. Physical activity is an important cause of asthma symptoms for most asthma patients and for some it is the only cause.

\section{Physical examination}

The most usual abnormal physical finding is wheezing on auscultation, a finding that confirms the presence of airflow limitation. However, in some people with asthma, wheezing may be absent or only detected when the person exhales forcibly, even in the presence of significant airflow limitation.

\section{Tests for diagnosis and monitoring}

Measurements of lung function

Although the diagnosis of asthma is usually based on the presence of characteristic symptoms, patients with asthma frequently have poor recognition of their symptoms and poor perception of symptom severity, especially if their asthma is long-standing [26]; assessment of symptoms such as dyspnoea and wheezing by physicians may also be inaccurate. For patients $>5 \mathrm{yrs}$ of age, measurements of lung function to confirm airflow limitation, and particularly the demonstration of reversibility of lung function abnormalities, greatly enhance diagnostic confidence. Quality control and adequate instruction for patients on how to perform the forced expiratory manoeuvre is essential [27-29].

The degree of reversibility in forced expiratory volume in one second (FEV1) that indicates a diagnosis of asthma is generally accepted as $\geqslant 12 \%$ and $\geqslant 200 \mathrm{~mL}$ from the pre-bronchodilator value [29]. However, most patients with controlled asthma will not exhibit reversibility at each assessment, particularly those on treatment, and the test therefore lacks sensitivity. Repeated testing at different visits is advised. Because many lung diseases may result in reduced FEV1, a useful assessment of airflow limitation is the ratio of FEV1 to forced vital capacity (FVC). The FEV1/FVC ratio is normally $>0.75-0.80$, and possibly $>0.90$ in children. Lower values suggest airflow limitation.

Peak expiratory flow (PEF) measurements made using a peak flow meter can also be an important aid in both diagnosis and monitoring of asthma. However, measurements of PEF are not interchangeable with other measurements of lung function, such as FEV1 in adults [30] or children [31], because values obtained with different peak flow meters vary and the range of predicted values is too wide. PEF measurements are also very effort dependent, and quality may be poor. Therefore, measurements should always be compared with the patient's own previous best measurements [32] using his/her own peak flow meter. The previous best measurement is usually obtained when the patient is asymptomatic and controlled.

The terms "reversibility" and "variability" refer to changes in symptoms accompanied by changes in airflow limitation that occur spontaneously or in response to treatment. The term reversibility is generally applied to rapid improvements in FEV1 (or PEF) measured within minutes after inhalation of a rapid-acting bronchodilator, e.g. after 200-400 $\mu \mathrm{g}$ salbutamol (albuterol), or more sustained improvement over days or weeks after the introduction of effective controller treatment, such as inhaled glucocorticosteroids [29]. Variability refers to improvement or deterioration in symptoms and lung function occurring over time. Variability may be experienced over the course of 1 day (when it is called diurnal variability), from day to day, from month to month, or seasonally. Obtaining a history of variability is an essential component of the diagnosis of asthma and forms part of the assessment of asthma control.

\section{Measurement of airway responsiveness}

For patients with symptoms consistent with asthma, but normal lung function, measurements of airway responsiveness to methacholine, histamine, mannitol, adenosine monophosphate 
or exercise challenge may help to establish a diagnosis of asthma [33].

\section{Measurements of allergic status}

Because of the strong association between asthma and allergic rhinitis, the presence of allergies, allergic diseases, and allergic rhinitis in particular, increases the probability of a diagnosis of asthma in patients with respiratory symptoms. The presence of allergies in asthma patients (identified by skin testing or measurement of specific immunoglobulin (Ig)E in serum) can help to identify risk factors that cause asthma symptoms in individual patients.

\section{Diagnostic challenges and differential diagnosis}

Children aged $\leqslant 5$ yrs

The diagnosis of asthma in early childhood is challenging and has to be based largely on clinical judgment and an assessment of symptoms and physical findings. Since the use of the label "asthma" for wheezing in children has important clinical consequences, it must be distinguished from other causes of persistent and recurrent wheeze. The categories of symptoms that are highly suggestive of a diagnosis of asthma include frequent episodes of wheeze (more than once a month), activity-induced cough or wheeze, nocturnal cough in periods without viral infections, absence of seasonal variation in wheeze, and symptoms that persist after 3 yrs of age. A large number of alternative causes of recurrent wheezing must be considered and excluded in this age group.

A useful method for confirming the diagnosis of asthma in children aged $\leqslant 5$ yrs is a trial of treatment with short-acting bronchodilators and inhaled glucocorticosteroids. Marked clinical improvement during the treatment, and deterioration when treatment is stopped, supports a diagnosis of asthma.

\section{Older children and adults}

A careful history and physical examination, together with the demonstration of reversible and variable airflow obstruction (preferably by spirometry), will in most instances confirm the diagnosis of asthma. Categories of alternative diagnoses to be considered in older children and adults include: hyperventilation syndrome and panic attacks; upper airway obstruction and inhaled foreign bodies [34]; vocal cord dysfunction [35]; other forms of obstructive lung disease, particularly chronic obstructive pulmonary disease (COPD); nonobstructive forms of lung disease (e.g. diffuse parenchymal lung disease); and nonrespiratory causes of symptoms (e.g. left ventricular failure).

The elderly

The frequent presence of comorbid diseases complicates the diagnosis of asthma in the elderly. A careful history and physical examination, combined with an ECG and chest radiograph, usually clarifies the picture, but treatment of both the asthma and, if present, comorbid conditions is often necessary to establish the contribution of each to a patient's symptoms. Distinguishing asthma from COPD is particularly difficult, and may require a trial of treatment with bronchodilators and/or oral/inhaled glucocorticosteroids.

\section{Distinguishing asthma from COPD}

COPD is characterised by airflow limitation that is not fully reversible, is usually progressive and is associated with an abnormal inflammatory response of the lungs to noxious particles or gases. Individuals with asthma who are exposed to noxious agents (particularly cigarette smoking) may develop fixed airflow limitation and a heterogenous inflammatory pattern can be found. Therefore, even though asthma can usually be distinguished from COPD, in some individuals who develop chronic respiratory symptoms and fixed airflow limitation it may be difficult to differentiate the two diseases. Symptom-based questionnaires for differentiating COPD and asthma for use by primary healthcare professionals are available [36, 37].

\section{Classification of asthma}

\section{Asthma severity}

Previous GINA documents subdivided asthma by severity, based on the level of symptoms, airflow limitation and lung function variability, into four categories: intermittent, mild persistent, moderate persistent or severe persistent (table 2; based on expert opinion rather than evidence). Classification of asthma by the severity of symptoms is useful when decisions are being made about management at the initial assessment of a patient. However, it is important to recognise that asthma severity involves both the severity of the underlying disease and its responsiveness to treatment. Severity is not an invariable feature of an individual patient's asthma but may change over months or years.

\section{TABLE 2 Classification of asthma severity by clinical} features before treatment

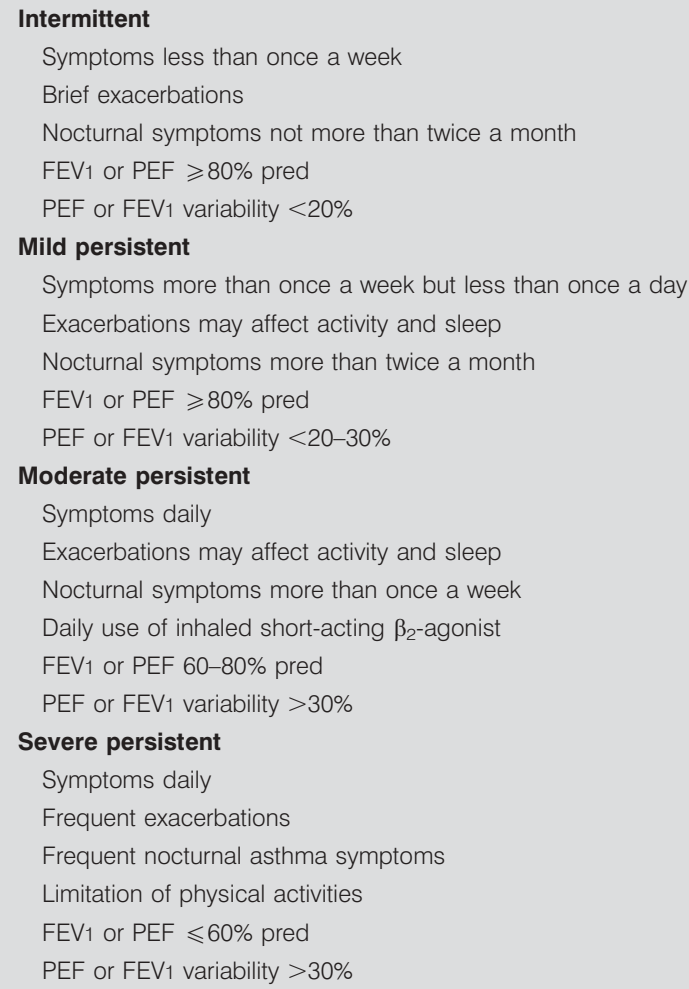

FEV1: forced expiratory volume in one second; PEF: peak expiratory flow; \% pred: \% predicted. 
Because of these considerations, the classification of asthma by severity is no longer recommended as the basis for ongoing treatment decisions but it may retain its value as a crosssectional means of characterising a group of patients with asthma who are not on inhaled glucocorticosteroid treatment, for selecting patients for inclusion in asthma studies. Its main limitation is its poor value in predicting what treatment will be required and what a patient's response to that treatment might be.

\section{Asthma control}

In general, the term control may indicate disease prevention or even cure. However, in asthma, where neither of these are realistic options at present, it refers to control of the manifestations of disease. There is evidence that reducing inflammation with controller therapy achieves clinical control, but because of the cost and/or general unavailability of tests to routinely assess airway inflammation [38-42], it is recommended that treatment is aimed at controlling the clinical features of disease, including lung function abnormalities. Table 3 provides the characteristics of controlled, partly controlled and uncontrolled asthma. This is a working scheme based on current opinion and has not been validated.

Complete control of asthma is commonly achieved with treatment, the aim of which should be to achieve and maintain control for prolonged periods [22] with due regard for the safety of treatment, potential for adverse effects, and the cost of treatment required to achieve this goal.

Validated measures for assessing the clinical control of asthma score goals as continuous variables and provide numerical values to distinguish different levels of control. Examples of validated instruments are: the Asthma Control Questionnaire [43, 44], Childhood Asthma Control Test [45], Asthma Control Test [46, 47], Asthma Therapy Assessment Questionnaire [48, 49] and Asthma Control Scoring System [50]. Not all of these instruments include a measure of lung function. Their value in clinical practice, as distinct from the research setting, although suggested in several reports, requires further evaluation.

\section{ASTHMA TREATMENTS}

Medications to treat asthma can be classified as controllers or relievers. Controllers are medications taken daily on a longterm basis to keep asthma under clinical control chiefly through their anti-inflammatory effects. Relievers are medications used on an as-needed basis, which act quickly to reverse bronchoconstriction and relieve its symptoms.

\section{Asthma medications: adults}

Asthma treatment for adults can be administered in different ways: inhaled, orally or parenterally (by subcutaneous, intramuscular or intravenous injection). The major advantage of inhaled therapy is that drugs are delivered directly into the airways, producing higher local concentrations with significantly lower risk of systemic side effects. Further information regarding various inhaler devices can be found from GINA [3].

\section{Controller medications}

Inhaled glucocorticosteroids

Role in therapy. Inhaled glucocorticosteroids are currently the most effective anti-inflammatory medications for the treatment of persistent asthma. Studies have demonstrated their efficacy in reducing asthma symptoms [51], improving quality of life [51], improving lung function [51], decreasing airway hyperresponsiveness [52], controlling airway inflammation [53], reducing frequency and severity of exacerbations [54] and reducing asthma mortality [55]. However, they do not cure asthma and when they are discontinued, deterioration of clinical control follows within weeks to months in a proportion of patients $[56,57]$.

Table 4 lists estimated equipotent doses of different inhaled glucocorticosteroids based upon the available efficacy literature, but the classification into dosage categories does not imply that clear dose-response relationships have been demonstrated for each drug. The efficacy of some products

TABLE 3 Levels of asthma control

\begin{tabular}{|c|c|c|c|}
\hline Characteristic & $\begin{array}{l}\text { Controlled } \\
\text { (all of the following) }\end{array}$ & $\begin{array}{l}\text { Partly controlled } \\
\text { (any measure present in any week) }\end{array}$ & Uncontrolled \\
\hline Daytime symptoms & None (twice or less per week) & More than twice a week & $\begin{array}{c}\text { Three or more features of partly controlled asthma } \\
\text { present in any week }\end{array}$ \\
\hline Limitations of activities & None (twice or less per week) & Any & $\begin{array}{c}\text { Three or more features of partly controlled asthma } \\
\text { present in any week }\end{array}$ \\
\hline $\begin{array}{l}\text { Nocturnal symptoms/ } \\
\text { awakening }\end{array}$ & None & Any & $\begin{array}{c}\text { Three or more features of partly controlled asthma } \\
\text { present in any week }\end{array}$ \\
\hline $\begin{array}{l}\text { Need for reliever/rescue } \\
\text { treatment }\end{array}$ & None (twice or less per week) & More than twice a week & $\begin{array}{c}\text { Three or more features of partly controlled asthma } \\
\text { present in any week }\end{array}$ \\
\hline $\begin{array}{l}\text { Lung function (PEF or } \\
\qquad \text { FEV } 1)^{\#}\end{array}$ & Normal & $<80 \%$ pred or personal best (if known) & $\begin{array}{c}\text { Three or more features of partly controlled asthma } \\
\text { present in any week }\end{array}$ \\
\hline Exacerbations & None & One or more per year & One in any week ${ }^{+}$ \\
\hline
\end{tabular}

PEF: peak expiratory flow; FEV1: forced expiratory volume in one second; \% pred: \% predicted. * : lung function is not a reliable test for children aged $\leqslant 5$ yrs; ${ }^{*}$ : any exacerbation should prompt review of maintenance treatment to ensure that it is adequate; ${ }^{+}$: by definition, an exacerbation in any week makes that an uncontrolled asthma week 
varies when administered via different inhaler devices [58]. Most of the benefit from inhaled glucocorticosteroids is achieved in adults at relatively low doses, equivalent to $400 \mu \mathrm{g}$ of budesonide per day [59]. (In this section, recommendations for doses of inhaled glucocorticosteroids are given as " $\mu \mathrm{g} \cdot$ day $^{-1}$ budesonide or equivalent", because a majority of the clinical literature on these medications uses this standard.) Increasing to higher doses provides little further benefit in terms of asthma control but increases the risk of side-effects $[59,60]$. However, there is marked individual variability of responsiveness to inhaled glucocorticosteroids, and because of this and the recognised poor adherence to treatment with inhaled glucocorticosteroids, many patients will require higher doses to achieve full therapeutic benefit. As tobacco smoking reduces the responsiveness to inhaled glucocorticosteroids, higher doses may be required in patients who smoke.

To reach clinical control, add-on therapy with another class of controller is preferable to increasing the dose of inhaled glucocorticosteroids. Some patients with severe asthma may benefit from long-term treatment with higher doses of inhaled glucocorticosteroids.

Side-effects. Systemic effects of inhaled glucocorticosteroids are not a problem in adults at doses of $\leqslant 400 \mu \mathrm{g}$ budesonide or equivalent daily. The systemic side-effects of long-term treatment with high doses of inhaled glucocorticosteroids include easy bruising [61], adrenal suppression [62, 63] and decreased bone mineral density [64, 65]. Inhaled glucocorticosteroids have also been associated with cataracts [66] and glaucoma in cross-sectional studies $[67,68]$, but there is no evidence of posterior-subcapsular cataracts in prospective studies [69-71].

\section{Leukotriene modifiers}

Role in therapy. Leukotriene modifiers include cysteinylleukotriene 1 receptor antagonists (montelukast, pranlukast and zafirlukast) and a 5-lipoxygenase inhibitor (zileuton).
Clinical studies have demonstrated that leukotriene modifiers have a small and variable bronchodilator effect, reduce symptoms (including cough) [72], improve lung function, and reduce airway inflammation and asthma exacerbations [73-75]. They may be used as an alternative treatment for adult patients with mild persistent asthma [76-78], and some patients with aspirin-sensitive asthma respond well to leukotriene modifiers [79]. However, when used alone as controller, the effects of leukotriene modifiers are less than those of low doses of inhaled glucocorticosteroids and, in patients already on inhaled glucocorticosteroids, leukotriene modifiers cannot substitute for this treatment without risking the loss of asthma control $[80,81]$. Leukotriene modifiers used as add-on therapy may reduce the dose of inhaled glucocorticosteroids required by patients with moderate to severe asthma [82], and may improve asthma control in patients whose asthma is not controlled with low or high doses of inhaled glucocorticosteroids [81, 83-85]. With the exception of one study that has demonstrated equivalence in preventing exacerbations [86], several studies have demonstrated that leukotriene modifiers are less effective than long-acting inhaled $\beta_{2}$-agonists as addon therapy [87-90].

Side-effects. Leukotriene modifiers are well tolerated, and few, if any, class-related effects have so far been recognised. Zileuton has been associated with liver toxicity and monitoring of liver tests is recommended during treatment with this medication. The apparent association of leukotriene modifiers with ChurgStrauss syndrome is probably largely the result of reductions in the doses of systemic and/or inhaled glucocorticosteroids unmasking the underlying disease, but a causal association in some patients cannot be entirely excluded [91-93].

Long-acting inhaled $\beta_{2}$-agonists

Role in therapy. Long-acting inhaled $\beta_{2}$-agonists, including formoterol and salmeterol, should never be used as monotherapy for asthma as these medications do not appear to influence the airway inflammation in asthma. They are most

\section{TABLE 4 Estimated equipotent daily doses of inhaled glucocorticosteroids for adults\#}

\section{Drug}

Low daily dose $\mu \mathrm{g}$

200-500

200-400

80-160

500-1000

100-250

200-400

400-1000
Medium daily dose $\mu \mathrm{g}$

$>500-1000$

$>400-800$

$>160-320$

$>1000-2000$

$>250-500$

$>400-800$

$>1000-2000$
High daily dose $\mu \mathrm{g}$

Triamcinolone acetonide

Notes. 1) The most important determinant of appropriate dosing is the clinician's judgment of the patient's response to therapy. The clinician must monitor the patient's response in terms of clinical control and adjust the dose accordingly. Once control of asthma is achieved, the dose of medication should be carefully titrated to the minimum dose required to maintain control, thus reducing the potential for adverse effects. 2) Designation of low, medium and high doses is provided from manufacturers' recommendations where possible. Clear demonstration of dose-response relationships is seldom provided or available. The principle is, therefore, to establish the minimum effective controlling dose in each patient, as higher doses may not be more effective and are likely to be associated with greater potential for adverse effects. 3) As CFC preparations are taken from the market, medication inserts for hydrofluoroalkane preparations should be carefully reviewed by the clinician for the equivalent correct dosage, as a low dose may be indicated. * : Comparisons based upon efficacy data. " Patients considered for high daily doses except for shor periods should be referred to a specialist for assessment to consider alternative combinations of controllers. Maximum recommended doses are arbitrary but with prolonged use are associated with increased risk of systemic side-effects. ${ }^{+}$: Approved for once-daily dosing in milder patients. 
effective when combined with inhaled glucocorticosteroids [94-96], and this combination therapy is the preferred treatment when a medium dose of inhaled glucocorticosteroid alone fails to achieve control of asthma. Addition of longacting inhaled $\beta_{2}$-agonists to a daily regimen of inhaled glucocorticosteroids improves symptom scores, decreases nocturnal asthma, improves lung function, decreases the use of rapid-acting inhaled $\beta_{2}$-agonists [97-99], reduces the number of exacerbations [54, 97-102] and achieves clinical control of asthma in more patients, more rapidly, and at a lower dose of inhaled glucocorticosteroids than inhaled glucocorticosteroids given alone [22]. Controlled studies have shown that delivering this therapy in a combination inhaler is as effective as giving each drug separately [103, 104].

Side-effects. Therapy with long-acting inhaled $\beta_{2}$-agonists causes fewer systemic adverse effects than oral therapy. The regular use of rapid-acting $\beta_{2}$-agonists in both short- and longacting forms may lead to relative refractoriness to $\beta_{2}$-agonists [105]. A possible increased risk of asthma-related death associated with the use of salmeterol in a small group of individuals [106] led to advisories that long-acting $\beta_{2}$-agonists are not a substitute for inhaled or oral glucocorticosteroids, and should only be used in combination with an appropriate dose of inhaled glucocorticosteroid as determined by a physician [107, 108].

\section{Theophylline}

Theophylline is a bronchodilator and, when given in a lower dose, has modest anti-inflammatory properties [109-111]. Sustained-release theophylline has little effect as a first-line controller [112] but may provide benefit, although less than that provided by long-acting inhaled $\beta_{2}$-agonists $[113,114]$, as addon therapy in patients who do not achieve control on inhaled glucocorticosteroids alone [115-117]. Side-effects of theophylline, particularly at higher doses $\left(\geqslant 10 \mathrm{mg} \cdot \mathrm{kg}^{-1}\right.$ body weight per day), are significant and detract from their usefulness but can be reduced by careful dose selection and monitoring, and generally decrease or disappear with continued use.

The role of cromones (sodium cromoglycate and nedocromil sodium) and oral long-acting $\beta_{2}$-agonists in asthma in adults is limited and their use is not recommended.

\section{Anti-lgE}

Role in therapy. Anti-IgE (omalizumab) is a treatment option limited to patients with elevated serum levels of IgE. Its current indication is for patients with severe allergic asthma [118] who are uncontrolled on high doses of inhaled glucocorticosteroids, although the dose of concurrent treatment has varied in different studies. Improved asthma control is reflected by fewer symptoms, less need for reliever medications and fewer exacerbations [119, 120].

Side-effects. For asthma patients already receiving treatment with glucocorticosteroids (inhaled and/or oral) and longacting $\beta_{2}$-agonists [118], anti-IgE appears to be safe as add-on therapy [121-123].

\section{Systemic glucocorticosteroids}

Role in therapy. Long-term oral glucocorticosteroid therapy (for periods $>2$ weeks as a glucocorticosteroid "burst") may be required for severely uncontrolled asthma but its use is limited by the risk of significant adverse effects. Oral preparations are preferred over parenteral (intramuscular or intravenous) for long-term therapy because of their lower mineralocorticoid effect, relatively short half-life and lesser effects on striated muscle, as well as the greater flexibility of dosing that permits titration to the lowest acceptable dose that maintains control.

Side-effects. The systemic side-effects of long-term oral or parenteral glucocorticosteroid treatment include osteoporosis, arterial hypertension, diabetes, hypothalamic-pituitary-adrenal (HPA) axis suppression, obesity, cataracts, glaucoma, skin thinning leading to cutaneous striae and easy bruising, and muscle weakness. Patients with asthma who are on long-term systemic glucocorticosteroids in any form should receive preventive treatment for osteoporosis [124-126]. Caution and close medical supervision are recommended when considering the use of systemic glucocorticosteroids in patients with asthma who also have tuberculosis, parasitic infections, osteoporosis, glaucoma, diabetes, severe depression or peptic ulcers. Fatal herpes virus infections have been reported among patients who are exposed to these viruses while taking systemic glucocorticosteroids, even a short course.

\section{Oral anti-allergic compounds}

In some countries, oral anti-allergic compounds have been introduced for the treatment of mild-to-moderate allergic asthma. In general, their anti-asthma effect appears to be limited [127] but studies on the relative efficacy of these compounds are needed before recommendations can be made about their role in the long-term treatment of asthma. Sedation is a potential side effect of some of these medications.

\section{Other controller therapies}

Role in therapy. Various therapeutic regimens to reduce the dose of oral glucocorticosteroids required by patients with severe asthma have been proposed. These medications should be used only in selected patients under the supervision of an asthma specialist, as their potential steroid-sparing effects may not outweigh the risk of serious side-effects. Two metaanalyses of the steroid-sparing effect of low-dose methotrexate showed a small overall benefit but a relatively high frequency of adverse effects $[128,129]$. This small potential to reduce the impact of glucocorticosteroid side-effects is probably insufficient to offset the adverse effects of methotrexate [130]. Cyclosporin [131] and gold [132, 133] have also been shown to be effective in some patients. The macrolide troleandromycin has a small steroid-sparing effect when used with systemic methylprednisolone, but its effect may result from the macrolide decreasing metabolism of the glucocorticosteroid and therefore not improve safety. However, other effects of the long-term use of macrolides in asthma remain under study [134]. The use of intravenous Ig is not recommended [135-137].

Side-effects. Macrolide use is frequently associated with nausea, vomiting, abdominal pain and, occasionally, liver toxicity. Methotrexate also causes gastrointestinal symptoms, hepatic and diffuse pulmonary parenchymal disease on rare occasions, and haematological and teratogenic effects. Cyclosporin may cause hypertension and renal impairment. 


\section{Allergen-specific immunotherapy}

The role of specific immunotherapy in adult asthma is limited. Appropriate immunotherapy requires the identification and use of a single well-defined clinically relevant allergen. The latter is administered in progressively higher doses in order to induce tolerance. A Cochrane Review, which examined 75 randomised controlled trials of specific immunotherapy compared with placebo, confirmed the efficacy of this therapy in reducing symptom scores and medication requirements in asthma, and improving allergen-specific and nonspecific airway hyperresponsiveness [138]. Similar modest effects were identified in a systematic review of sublingual immunotherapy [139]. The value of immunotherapy using multiple allergens does not have support. Side-effects range from localised reactions at the injection site to life-threatening anaphylactic reactions.

\section{Reliever medications}

Rapid-acting inhaled $\beta_{2}$-agonists

Rapid-acting inhaled $\beta_{2}$-agonists are the medications of choice for quick relief of bronchospasm during acute exacerbations of asthma and for the pretreatment of exercise-induced bronchoconstriction. They should be used only on an as-needed basis at the lowest dose and frequency required. Increased use, especially daily use, is a warning of deterioration of asthma control and indicates the need to reassess treatment. Similarly, failure to achieve a quick and sustained response to $\beta_{2}$-agonist treatment during an exacerbation mandates medical attention and may indicate the need for short-term treatment with oral glucocorticosteroids. Side-effects such as tremor and tachycardia occur with higher doses.

\section{Anticholinergics}

Role in therapy. Inhaled ipratropium bromide is a less effective reliever medication in asthma than rapid-acting inhaled $\beta_{2^{-}}$ agonists and it is not recommended for the long-term management of asthma, except as an alternative bronchodilator for patients who experience tachycardia, arrhythmia and tremor from rapid-acting $\beta_{2}$-agonists.

Side-effects. Side-effects include dryness of the mouth and a bitter taste, but there is no evidence of a drying effect on airway mucus [140].

\section{Short-acting oral $\beta_{2}$-agonists}

Short-acting oral $\beta_{2}$-agonists are appropriate for use in the few patients who are unable to use inhaled medication. However, their use is associated with a higher prevalence of adverse effects.

\section{Complementary and alternative medicine}

Complementary and alternative therapies in general have not been shown to be effective in the management of asthma.

\section{Asthma treatment: children}

Route of administration

Inhaled therapy is the cornerstone of asthma treatment for children of all ages. Different age groups require different inhalers for effective therapy, so the choice of inhaler must be individualised. Information about the lung dose for a particular drug formulation is seldom available for children, and marked differences exist between the various inhalers. This should be considered whenever one inhaler device is substituted with another. In addition, the choice of inhaler device should include consideration of the efficacy of drug delivery, cost, safety, ease of use, convenience, and documentation of its use in the patient's age group [141-143]. In general, a metered-dose inhaler (MDI) with spacer is preferable to nebulised therapy due to its greater convenience, more effective lung deposition, lower risk of side-effects and lower cost. During acute asthma attacks, an MDI should always be used with a spacer, as in this situation a child may be unable to correctly coordinate inhalation with actuation of the MDI. Commercially produced spacers with well-characterised drug output characteristics are preferable.

\section{TABLE 5 Estimated equipotent daily doses of inhaled glucocorticosteroids for children\#}

\section{Drug}

Low daily dose $\mu \mathrm{g}$
Medium daily dose $\mu \mathrm{g}$
High daily dose $\mu \mathrm{g}^{\circ}$

\section{Beclomethasone dipropionate \\ Budesonide $^{+}$ \\ Ciclesonide $^{+}$ \\ Flunisolide \\ Fluticasone propionate \\ Mometasone furoate ${ }^{+}$ \\ Triamcinolone acetonide}

$\begin{array}{ccc}100-200 & >200-400 & >400 \\ 100-200 & >200-400 & >400 \\ 80-160 & >160-320 & >320 \\ 500-750 & >750-1250 & >1250 \\ 100-200 & >200-500 & >500 \\ 100-200 & >200-400 & >400 \\ 400-800 & >800-1200 & >1200\end{array}$

Notes. 1) The most important determinant of appropriate dosing is the clinician's judgment of the patient's response to therapy. The clinician must monitor the patient's response in terms of clinical control and adjust the dose accordingly. Once control of asthma is achieved, the dose of medication should be carefully titrated to the minimum dose required to maintain control, thus reducing the potential for adverse effects. 2) Designation of low, medium and high doses is provided from manufacturers' recommendations where possible. Clear demonstration of dose-response relationships is seldom provided or available. The principle is, therefore, to establish the minimum effective controlling dose in each patient, as higher doses may not be more effective and are likely to be associated with greater potential for adverse effects. 3) As CFC preparations are taken from the market, medication inserts for hydrofluoroalkane preparations should be carefully reviewed by the clinician for the equivalent correct dosage. ${ }^{*}$ : Comparisons based upon efficacy data. ${ }^{\bullet}$ : Patients considered for high daily doses except for short periods should be referred to a specialist for assessment to consider alternative combinations of controllers. Maximum recommended doses are arbitrary but with prolonged use are associated with increased risk of systemic side-effects. ${ }^{+}$: Approved for once-daily dosing in mild patients. 
Nebulisers have rather imprecise dosing, are expensive, are time consuming to use and care for and require maintenance. They are mainly reserved for children who cannot use other inhaler devices. In severe acute asthma exacerbations, a nebuliser is often used, although an MDI with a spacer is equally effective [144].

\section{Controller medications}

Controller medications for children include inhaled and systemic glucocorticosteroids, leukotriene modifiers, longacting inhaled $\beta_{2}$-agonists, theophylline and cromones.

\section{Inhaled glucocorticosteroids}

Role in therapy. Inhaled glucocorticosteroids are the most effective controller therapy for asthma for children of all ages. Table 5 lists estimated equipotent doses of different inhaled glucocorticosteroids administered via different inhalation devices.

Children aged $>5$ yrs. Dose-response and dose titration studies in children [145, 146] demonstrate marked and rapid clinical improvements in symptoms and lung function at low doses of inhaled glucocorticosteroids (e.g. 100-200 $\mu$ g budesonide daily) [147-151] in a majority of patients [149], but some patients require higher doses $\left(400 \mu \mathrm{g} \cdot \mathrm{day}^{-1}\right)$ [148, 151]. When glucocorticosteroid treatment is discontinued, asthma control deteriorates within weeks to months [52].

Children aged $\leqslant 5$ yrs. Treatment with inhaled glucocorticosteroids in children aged $\leqslant 5$ yrs with asthma generally produces similar clinical effects as in older children, but dose-response relationships have been less well studied. The clinical response may differ depending on the inhaler and the child's ability to use the inhaler correctly. With use of a spacer device, daily doses $\leqslant 400 \mu \mathrm{g}$ of budesonide or equivalent result in nearmaximum benefits in the majority of patients [152, 153]. Use of inhaled glucocorticosteroids does not induce remission of asthma and it returns when treatment is stopped [154].

The clinical benefits of intermittent systemic or inhaled glucocorticosteroids for children with intermittent, viral-induced wheeze remain controversial [155]. There is no evidence to support the use of maintenance low-dose inhaled glucocorticosteroids for preventing early transient wheezing [154-156].

Side-effects. The majority of studies evaluating the systemic effects of inhaled glucocorticosteroids have been undertaken in children aged $>5$ yrs.
A summary of the findings of studies on inhaled glucocorticosteroids and growth is provided in table 6 .

The potential clinically relevant adverse effects of inhaled glucocorticosteroids on bones in children are osteoporosis and fracture. The conclusions from several studies [52, 149, 160166] are summarised in table 7.

Treatment with inhaled glucocorticosteroid doses of $<200 \mu \mathrm{g}$ budesonide or equivalent daily is normally not associated with significant suppression of the HPA axis in children [52]. However, adrenal crisis has been reported in children treated with excessively high doses [167].

Inhaled glucocorticosteroids have not been associated with an increased occurrence of cataract development in children [52, 69].

Although isolated case reports have suggested that hyperactive behaviour, aggressiveness, insomnia, uninhibited behaviour and impaired concentration may be seen with inhaled glucocorticosteroid treatment, no increase in such central nervous system effects has been found in two long-term controlled trials of inhaled budesonide involving $>10,000$ treatment-yrs [52, 149].

Clinical thrush is seldom a problem in children treated with inhaled or systemic glucocorticosteroids. The occurrence of hoarseness or other noticeable voice changes during budesonide treatment is similar to placebo [69]. Treatment with an average daily dose of $500 \mu \mathrm{g}$ budesonide for 3-6 yrs is not associated with an increased tendency to bruise [69].

With regard to dental side-effects, inhaled glucocorticosteroid treatment is not associated with increased incidence of caries. However, the increased level of dental erosion reported in children with asthma [168] may be due to a reduction in oral $\mathrm{pH}$ that could result from inhalation of $\beta_{2}$-agonists [169].

The long-term use of inhaled glucocorticosteroids is not associated with other local side-effects, such as an increased incidence of lower respiratory tract infections, including tuberculosis.

\section{Leukotriene modifiers}

Children aged $>5$ yrs. Leukotriene modifiers provide clinical benefit in children aged $>5$ yrs at all levels of severity [170174] but less than that of low-dose inhaled glucocorticosteroids [175]. Leukotriene modifiers provide partial protection against exercise-induced bronchoconstriction within hours after

\section{TABLE 6 Summary of glucocorticosteroids and growth in children}

Uncontrolled or severe asthma adversely affects growth and final adult height

No long-term controlled studies have reported any statistically or clinically significant adverse effects on growth of $100-200 \mu g \cdot d a y^{-1}$ of inhaled glucocorticosteroids

Growth retardation may be seen with all inhaled glucocorticosteroids when a high dose is administered

Growth retardation in both short- and medium-term studies is dose dependent

Important differences seem to exist between the growth-retarding effects of various inhaled glucocorticosteroids and inhalers

Different age groups seem to differ in their susceptibility to the growth-retarding effects of inhaled glucocorticosteroids; children aged 4-10 yrs are more susceptible

than adolescents

Glucocorticosteroid-induced changes in growth rate during the first year of treatment appear to be temporary

Children with asthma treated with inhaled glucocorticosteroids attain normal adult height (predicted from family members) but at a later age 


\section{TABLE 7 Summary of bones and glucocorticosteroids in children}

No studies have reported any statistically significant increased risk of fractures in children taking inhaled glucocorticosteroids

Oral or systemic glucocorticosteroid use increases the risk of fracture. The risk of fracture increases along with the number of treatments, with a $32 \%$ increase at four courses ever. Use of inhaled glucocorticosteroids reduces the need for systemic courses

Controlled longitudinal studies of 2-5 yrs' duration and several cross-sectional studies found no adverse effects of inhaled glucocorticosteroid treatment on bone mineral density

No prospective studies have followed children on inhaled glucocorticosteroid treatment until peak bone mineral density has been reached

Data are taken from $[52,160,161]$

administration with no loss of bronchoprotective effects [176]. As add-on treatment in children whose asthma is insufficiently controlled by low doses of inhaled glucocorticosteroids, leukotriene modifiers provide moderate clinical improvements, including a significant reduction in exacerbations $[177,178]$. However, combination therapy is less effective in controlling asthma in children with moderate persistent asthma than increasing to moderate doses of inhaled glucocorticosteroid [179].

Children aged $\leqslant 5$ yrs. In addition to the efficacy as described previously [180, 181], leukotriene modifiers reduce viralinduced asthma exacerbations in children aged 2-5 yrs with a history of intermittent asthma [180].

Side-effects. No safety concerns have been demonstrated from the use of leukotriene modifiers in children.

\section{Long-acting inhaled $\beta_{2}$-agonists}

Role in therapy. Long-acting inhaled $\beta_{2}$-agonists are primarily used as add-on therapy in children aged $>5$ yrs whose asthma is insufficiently controlled by moderate doses of inhaled glucocorticosteroids or as single-dose therapy before vigorous exercise. Monotherapy with long-acting inhaled $\beta_{2}$-agonists should be avoided [106]. Combination products containing an inhaled glucocorticosteroid and a long-acting inhaled $\beta_{2^{-}}$ agonist are preferred to long-acting inhaled $\beta_{2}$-agonist and inhaled glucocorticosteroids administered by separate inhalers. The effect of long-acting inhaled $\beta_{2}$-agonists or combination products has not yet been adequately studied in children aged $\leqslant 5$ yrs.

Side-effects. Although long-acting inhaled $\beta_{2}$-agonists are welltolerated in children, even after long-term use, because of inconsistency of reports on their effects on exacerbations of asthma, they are not the recommended option when more than one controller is required [182]. If used, long-acting $\beta_{2}$-agonists should only be used in combination with an appropriate dose of inhaled glucocorticosteroid as determined by a physician, preferably in a fixed combination inhaler.

\section{Theophylline}

Role in therapy. Theophylline has been shown to be effective as monotherapy and as add-on treatment to inhaled or oral glucocorticosteroids in children aged $>5$ yrs. It is significantly more effective than placebo at controlling day and night symptoms and improving lung function [183-185]. Maintenance treatment offers a marginal protective effect against exercise-induced bronchoconstriction [186]. Add-on treatment with theophylline has been found to improve asthma control and reduce the maintenance glucocorticosteroid dose necessary in children with severe asthma treated with inhaled or oral glucocorticosteroids [187, 188]. A few studies in children aged $\leqslant 5$ yrs also suggest some clinical benefit. However, the efficacy of theophylline is less than that of low-dose inhaled glucocorticosteroids. Sustained-release products are preferable for maintenance therapy, since they enable twice-daily dosing. Measurement of plasma theophylline levels is not necessary in otherwise healthy children when doses $<10 \mathrm{mg} \cdot \mathrm{kg}^{-1} \cdot \mathrm{day}^{-1}$ are used. However, when higher doses are used or when drugs that may increase theophylline levels are also used chronically, plasma theophylline levels should be measured $2 \mathrm{~h}$ before administration of the next dose once steady state has been reached (after 3 days).

Side-effects. The most common side-effects of theophylline are anorexia, nausea, vomiting and headache [189]. Mild central nervous stimulation, palpitations, tachycardia, arrhythmias, abdominal pain, diarrhoea and, rarely, gastric bleeding may also occur. These side-effects are mainly seen at doses $>10 \mathrm{mg} \cdot \mathrm{kg}^{-1} \cdot \mathrm{day}^{-1}$. The risk of adverse effects is reduced if treatment is initiated with daily doses $\sim 5 \mathrm{mg} \cdot \mathrm{kg}^{-1} \cdot \mathrm{day}^{-1}$ and then gradually increased to $10 \mathrm{mg} \cdot \mathrm{kg}^{-1} \cdot \mathrm{day}^{-1}$. Severe overdosing with theophylline can be fatal.

\section{Cromones: sodium cromoglycate and nedocromil sodium}

Sodium cromoglycate and nedocromil sodium have a limited role in the long-term treatment of asthma in children.

\section{Long-acting oral $\beta_{2}$-agonists}

Due to the potential side-effects of cardiovascular stimulation, anxiety and skeletal muscle tremor, treatment with long-acting oral $\beta_{2}$-agonists is not encouraged. If used, dosing should be individualised, and the therapeutic response monitored to limit side-effects [190]. Long-acting oral $\beta_{2}$-agonist therapy offers little or no protection against exercise-induced bronchoconstriction.

\section{Systemic glucocorticosteroids}

Because of the side-effects of prolonged use, oral glucocorticosteroids in children with asthma should be restricted to the treatment of acute severe exacerbations, whether viral-induced or otherwise.

\section{Reliever medications}

Rapid-acting and short-acting oral $\beta_{2}$-agonists.

Role in therapy. Rapid-acting inhaled $\beta_{2}$-agonists are the most effective bronchodilators available and are therefore the preferred treatment for acute asthma in children of all ages. 
The inhaled route results in more rapid bronchodilation at a lower dose and with fewer side-effects than oral or intravenous administration [191]. Furthermore, inhaled therapy offers significant protection against exercise-induced bronchoconstriction and other challenges for $0.5-2 \mathrm{~h}$ (long-acting $\beta_{2^{-}}$ agonists offer longer protection) [192]. This is not seen after systemic administration [193]. Oral therapy is rarely needed and reserved mainly for young children who cannot use inhaled therapy.

Side-effects. Skeletal muscle tremor, headache, palpitations and some agitation are the most common complaints associated with high doses of $\beta_{2}$-agonists in children. These complaints are more common after systemic administration and disappear with continued treatment [194].

\section{Anticholinergics}

Inhaled anticholinergics are not recommended for long-term management of asthma in children [195].

\section{ASTHMA MANAGEMENT AND PREVENTION}

Clinical studies have shown that asthma can be effectively controlled by intervening to suppress and reverse the inflammation, as well as treating the bronchoconstriction and related symptoms. Furthermore, early intervention to stop exposure to the risk factors that sensitised the airway may help improve the control of asthma and reduce medication needs. The recommendations for asthma management are described in five interrelated components of therapy and have the following major goals: 1) to achieve and maintain control of symptoms; 2) to maintain normal activity levels, including exercise; 3) to maintain pulmonary function as close to normal as possible; 4) to prevent asthma exacerbations; 5) to avoid adverse effects from asthma medications; and 6) to prevent asthma mortality.

\section{Component 1: develop patient-doctor partnership}

The effective management of asthma requires the development of a partnership between the person with asthma and his or her healthcare professional(s) (and parents/caregivers in the case of children with asthma). The aim of this partnership is to enable patients with asthma to gain the knowledge, confidence and skills to assume a major role in the management of their asthma. The partnership is formed and strengthened as patients and their healthcare professionals discuss and agree on the goals of treatment, develop a personalised, written selfmanagement action plan including self-monitoring, and periodically review the patient's treatment and level of asthma control.

This approach, guided self-management, has been shown to reduce asthma morbidity in both adults (Evidence $\mathrm{A}$ ) and children (Evidence A). A number of specific systems of guided self-management have been developed [196-205] for use in a wide range of settings, including primary care [197, 201, 205], hospitals [196, 198, 200, 204], emergency departments [199] and internet-based home monitoring [206], and among such diverse groups as pregnant women with asthma [207], children and adolescents [208, 209], and in multi-racial populations [210]. Guided self-management may involve varying degrees of independence, ranging broadly from patient-directed selfmanagement, in which patients make changes without reference to their caregiver but in accordance with a prior written action plan, to doctor-directed self-management, in which patients follow a written action plan but refer most major treatment changes to their physician at the time of planned or unplanned consultations. A series of Cochrane Systematic Reviews [208, 211-214] have examined the role of education and self-management strategies in the care of asthma patients.

\section{Asthma education}

Education should be an integral part of all interactions between healthcare professionals and patients, and is relevant to asthma patients of all ages. All individuals require certain core information and skills, but most education must be personalised and given to the person in a number of steps. Social and psychological support may also be required to maintain positive behavioural change.

Good communication is essential as the basis for subsequent good compliance and adherence (Evidence B) [215-218]. Teaching healthcare professionals to improve their communication skills can result in measurably better outcomes, including increased patient satisfaction, better health and reduced use of healthcare, and these benefits may be achieved without any increase in consultation times [219]. Patients should be taught how to give information to doctors in a clearer manner; information-seeking techniques and methods of checking their understanding of what the doctor had told them gained significant improvements in compliance and overall health [220].

Early in the consultation the patient needs information about diagnosis and simple information about types of treatment available, the rationale for specific therapeutic interventions being recommended, and strategies for avoiding factors that cause asthma symptoms. Verbal information should be supplemented by the provision of written or pictorial [221, 222] information about asthma and its treatment. Different inhaler devices can be demonstrated and the person with asthma encouraged to participate in the decision as to which is most suitable for them. Criteria for the initial selection of inhaler device include device availability and cost, patient skills, and preferences of the health professional and patient $[142,223,224]$. Patients should be given adequate opportunity to express their expectations of both their asthma and its treatment. A frank appraisal should be made of how far their expectations may or may not be met, and agreement should be made about specific goals for therapy.

Personal asthma action plans help individuals with asthma make changes to their treatment in response to changes in their level of asthma control, as indicated by symptoms and/or peak expiratory flow, in accordance with written predetermined guidelines [225-227]. The effects were greatest where the intervention involved each of the following elements: education, self-monitoring, regular review and patient-directed selfmanagement using a written self-management action plan (Evidence A). Patients who are unable to undertake guided self-management can still achieve benefit from a structured programme of regular medical review. Examples of selfmanagement plans can be found on several websites: UK National Asthma Campaign Plan [228]; International Asthma 
Management Plan "Zone System" [229]; and New Zealand "Credit Card" System [230].

Follow-up consultations should take place at regular intervals. Patient's questions are discussed, and any problems with asthma and its initial treatment are reviewed. Inhaler device technique should be assessed regularly and corrected if inadequate [231]. Follow-up consultations should also include checking adherence/compliance to the medication plan and recommendations for reducing exposure to risk factors. Symptoms (and, where appropriate, home peak flow recordings) noted in the diary are also reviewed regularly. After a period of initial training, the frequency of home peak flow and symptom monitoring depends in part on the level of control of the person's asthma. The written self-management plan and its understanding are also reviewed. Educational messages should be reviewed and repeated or added to if necessary.

\section{Improving adherence}

Studies of adults and children [232] have shown that $~ 50 \%$ of those on long-term therapy fail to take medications as directed at least part of the time. Nonadherence may be defined in a nonjudgmental way as the failure of treatment to be taken as agreed upon by the patient and the healthcare professional. Nonadherence may be identified by prescription monitoring, pill counting or drug assay, but at a clinical level it is best detected by asking about therapy in a way that acknowledges the likelihood of incomplete adherence.

\section{The education of others}

The education of the general public, especially in a school or occupational setting, about asthma is helpful in that it enables members of the public to recognise asthma symptoms and their consequences and encourages those with asthma to seek medical attention and follow their asthma-management programme.

\section{Component 2: identify and reduce exposure to risk factors}

Although pharmacological intervention to treat established asthma is highly effective in controlling symptoms and improving quality of life, measures to prevent the development of asthma, asthma symptoms, and asthma by avoiding or reducing exposure to risk factors should be implemented wherever possible [233]. Few measures can be recommended for prevention of asthma because the development of the disease is complex and incompletely understood. Until such measures are developed, prevention efforts must primarily focus on prevention of asthma symptoms and attacks.

\section{Asthma prevention}

Other than preventing tobacco exposure both in utero and after birth, there are no proven and widely accepted interventions that can prevent the development of asthma.

Allergic sensitisation can occur pre-natally [234, 235] but there is insufficient information on the critical doses and timing of allergen exposure to permit intervention in this process, and no strategies can be recommended to prevent allergic sensitisation pre-natally. The role of diet, particularly breastfeeding, in relation to the development of asthma has been extensively studied and, in general, infants fed formulas of intact cow's milk or soy protein compared with breast milk have a higher incidence of wheezing illnesses in early childhood [236]. Exclusive breast-feeding during the first months after birth is associated with lower asthma rates during childhood [237].

The "hygiene hypothesis" of asthma, although controversial, has led to the suggestion that strategies to prevent allergic sensitisation should focus on redirecting the immune response of infants toward a type 1 helper T-cell, nonallergic response or on modulating T-regulator cells [238], but such strategies currently remain in the realm of hypothesis and require further investigation.

Exposure to tobacco smoke, both pre-natally and post-natally, is associated with measurable harmful effects, including effects on lung development [239] and a greater risk of developing wheezing illnesses in childhood [240]. Pregnant females and parents of young children should be advised not to smoke (Evidence B).

\section{Prevention of asthma symptoms and exacerbations}

Asthma exacerbations may be caused by a variety of factors, sometimes referred to as "triggers", including allergens, viral infections, pollutants and drugs. Reducing a patient's exposure to some of these categories of risk factors (e.g. smoking cessation, reducing exposure to second-hand smoke, reducing or eliminating exposure to occupational agents known to cause symptoms and avoiding foods/additives/drugs known to cause symptoms) improves the control of asthma and reduces medication needs. In the case of other factors (e.g. allergens, viral infections and pollutants), measures should be taken to avoid these, where possible. Because many asthma patients react to multiple factors that are ubiquitous in the environment, avoiding these factors completely is usually impractical and very limiting to the patient. Therefore, medications to maintain asthma control have an important role because patients are often less sensitive to these risk factors when their asthma is under good control.

\section{Indoor allergens}

Among the wide variety of allergen sources in human dwellings are domestic mites, furred animals, cockroaches and fungi. However, there is conflicting evidence about whether measures to create a low-allergen environment in patients' homes and reduce exposure to indoor allergens are effective at reducing asthma symptoms [241]. The majority of single interventions have failed to achieve a sufficient reduction in allergen load to lead to clinical improvement [241-243]. It is likely that no single intervention will achieve sufficient benefits to be cost effective.

\section{Outdoor allergens}

Outdoor allergens, such as pollens and moulds, are impossible to avoid completely. Exposure may be reduced by closing windows and doors, remaining indoors when pollen and mould counts are highest, and using air conditioning if possible. Some countries use radio, television and the internet to provide information on outdoor allergen levels. The impact of these measures is difficult to assess. 


\section{Indoor air pollutants}

Parents/caregivers of children with asthma should be advised not to smoke and not to allow smoking in rooms their children use. In addition to increasing asthma symptoms and causing long-term impairments in lung function, active cigarette smoking reduces the efficacy of inhaled and systemic glucocorticosteroids (Evidence B) [19, 21], and smoking cessation needs to be vigorously encouraged for all patients with asthma who smoke [244]. Other major indoor air pollutants include nitric oxide, nitrogen oxides, carbon monoxide, carbon dioxide, sulfur dioxide, formaldehyde and biologicals (endotoxin) [245]. However, methods to control or prevent exposure to these pollutants, such as venting all furnaces to the outdoors and maintaining heating systems adequately, have not been adequately evaluated and can be expensive (Evidence D).

\section{Outdoor air pollutants}

Outbreaks of asthma exacerbations have been shown to occur in relationship to increased levels of air pollutants, such as ozone, nitrogen oxides, acidic aerosols and particulate matter, and this may be related to a general increase in pollutant levels or to an increase in specific allergens to which individuals are sensitised [246-248]. On occasion, certain weather and atmospheric conditions, e.g. thunderstorms [249], favour the development of asthma exacerbations by a variety of mechanisms, including dust and pollution, increases in respirable allergens and changes in temperature/humidity. Avoidance of unfavourable environmental conditions is usually unnecessary for patients whose asthma is controlled. For patients with asthma that is difficult to control, practical steps to take during unfavourable environmental conditions include: avoiding strenuous physical activity in cold weather, low humidity or high air pollution; avoiding smoking and smoke-filled rooms; and staying indoors in a climate-controlled environment.

\section{Occupational exposures}

The early identification of occupational sensitisers and the removal of sensitised patients from any further exposure are important aspects of the management of occupational asthma (Evidence B). Once a patient has become sensitised to an occupational allergen, the level of exposure necessary to induce symptoms may be extremely low, and resulting exacerbations become increasingly severe.

\section{Food and food additives}

Food allergy as an exacerbating factor for asthma is uncommon and occurs primarily in young children. Food avoidance should not be recommended until an allergy has been clearly demonstrated (usually by oral challenges) [250]. When food allergy is demonstrated, food allergen avoidance can reduce asthma exacerbations (Evidence D) [251].

\section{Drugs}

Some medications can exacerbate asthma. Aspirin and other nonsteroidal anti-inflammatory drugs can cause severe exacerbations and should be avoided in patients with a history of reacting to these agents [252]. $\beta$-Blocker drugs administered orally or intraocularly may exacerbate bronchospasm (Evidence A) and close medical supervision is essential when these are used by patients with asthma [253].

\section{Influenza vaccination}

Patients with moderate-to-severe asthma should be advised to receive an influenza vaccination every year [254], or at least when vaccination of the general population is advised. However, routine influenza vaccination of children [255] and adults [256] with asthma does not appear to protect them from asthma exacerbations or improve asthma control.

\section{Obesity}

Increases in body mass index have been associated with increased prevalence of asthma, although the mechanisms behind this association are unclear [257]. Weight reduction in obese patients with asthma has been demonstrated to improve lung function, symptoms, morbidity and health status (Evidence B) [258].

\section{Emotional stress}

Emotional stress may lead to asthma exacerbations, primarily because extreme emotional expressions (laughing, crying, anger or fear) can lead to hyperventilation and hypocapnia, which can cause airway narrowing [259, 260]. Panic attacks, which are rare but not exceptional in some patients with asthma, have a similar effect [261, 262]. However, it is important to note that asthma is not primarily a psychosomatic disorder.

\section{Other factors that may exacerbate asthma}

Rhinitis, sinusitis and polyposis are frequently associated with asthma and need to be treated. In children, antibiotic treatment of bacterial sinusitis has been shown to reduce the severity of asthma [263]. However, sinusitis and asthma may simply coexist. Apart from sinusitis, there is little evidence that bacterial infections exacerbate asthma. Gastro-oesophageal reflux can exacerbate asthma, especially in children, and asthma sometimes improves when the reflux is corrected $[264,265]$. Many females complain that their asthma is worse at the time of menstruation, and pre-menstrual exacerbations have been documented [266]. Similarly, asthma may improve, worsen or remain unchanged during pregnancy [267].

\section{Component 3: assess, treat and monitor asthma}

The goal of asthma treatment, to achieve and maintain clinical control, can be reached in a majority of patients [22] with a pharmacological intervention strategy developed in partnership between the patient/family and the doctor. Each patient is assigned to one of five "treatment steps", depending on their current level of control, and treatment is adjusted in a continuous cycle driven by changes in their asthma control status. This cycle involves: assessing asthma control; treating to achieve control; and monitoring to maintain control. In this Component, this cycle is described for long-term treatment of asthma. Treatment for exacerbations is detailed in Component 4.

\section{Assessing asthma control}

Each patient should be assessed to establish his/her current treatment regimen, adherence to the current regimen and level of asthma control. A simplified scheme for recognising controlled, partly controlled and uncontrolled asthma in a given week is provided in table 3. Several composite control measures [44, 47, 268, 269] have been developed and are being validated for use by healthcare providers to assess the state of 
control of their patients' asthma and by patients for selfassessments [270] as part of a written personal asthma action plan. Uncontrolled asthma may progress to the point of an exacerbation, and immediate steps, described in Component 4, should be taken to regain control.

\section{Treating to achieve control}

The patient's current level of asthma control and current treatment determine the selection of pharmacological treatment. For example, if asthma is not controlled by the current treatment regimen, treatment should be stepped up until control is achieved. If control has been maintained for $\geqslant 3$ months, treatment can be stepped down with the aim of establishing the lowest step and dose of treatment that maintains control (Evidence D; see Monitoring to maintain control, later). If asthma is partly controlled, an increase in treatment should be considered, subject to whether more effective options are available (e.g. increased dose or an additional treatment), safety and cost of possible treatment options, and the patient's satisfaction with the level of control achieved. The scheme presented in figure 1 is based upon these principles, but the range and sequence of medications used in each clinical setting will vary depending on local availability (for cost or other reasons), acceptability and preference.

\section{Treatment steps for achieving control}

Steps 1-5 provide options of increasing efficacy, with the exception of Step 5, where issues of availability and safety influence the selection of treatment. Step 2 is the initial treatment for most treatment-naïve patients with persistent asthma symptoms. If symptoms at the initial consultation suggest that asthma is severely uncontrolled, treatment should be commenced at Step 3 .

At each treatment step, a reliever medication (rapid-onset bronchodilator, either short- or long-acting) should be provided for quick relief of symptoms. However, regular use of reliever medication is one of the elements defining uncontrolled asthma, and indicates that controller treatment should be increased. Therefore, reducing or eliminating the need for reliever treatment is both an important goal and a measure of success of treatment. For Steps 2-5, a variety of controller medications are available.

Step 1: As-needed reliever medication. Step 1 treatment with an asneeded reliever medication is reserved for untreated patients

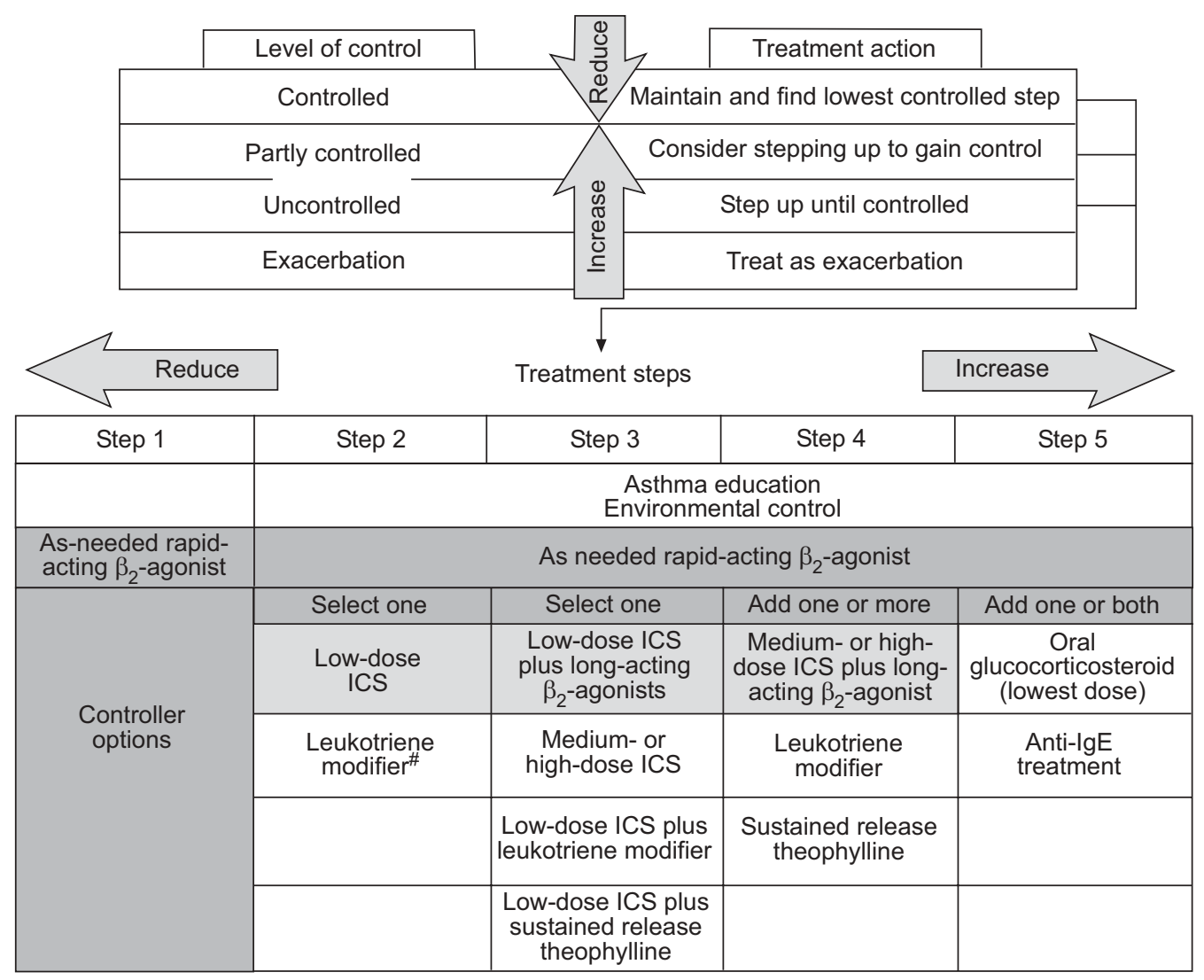

FIGURE 1. Management approach based on control for children $>5$ yrs of age, adolescents and adults. Alternative reliever treatments include inhaled anticholinergics, short-acting oral $\beta_{2}$-agonists, some long-acting $\beta_{2}$-agonists and short-acting theophylline. Regular dosing with short- and long-acting $\beta_{2}$-agonist is not advised unless accompanied by regular use of an inhaled glucocorticosteroid (ICS). The available literature on treatment of asthma in children aged $\leqslant 5$ yrs precludes treatment recommendations. The best-documented treatment to control asthma in this age group is ICS and, at step 2, a low-dose ICS is recommended as the initial controller treatment. Equivalent doses of ICSS, some of which may be given as a single daily dose, are provided in table 5. 1 : : preferred controller options. \#: receptor antagonist or synthesis inhibitors. 
with occasional daytime symptoms (cough, wheeze, dyspnoea occurring twice or less per week, or less frequently if nocturnal) of short duration (lasting only a few hours) comparable to controlled asthma. Between episodes, the patient is asymptomatic with normal lung function and there is no nocturnal awakening. When symptoms are more frequent and/or worsen periodically, patients require regular controller treatment (see Step 2 or higher) in addition to as-needed reliever medication (Evidence B) [149, 271, 272].

For the majority of patients in Step 1 , a rapid-acting inhaled $\beta_{2^{-}}$ agonist is the recommended reliever treatment (Evidence A) [273].

Bronchoconstriction occurring after or during prolonged exercise often indicates that the patient's asthma is not well controlled, and stepping up controller therapy generally results in improvement. For those patients who still experience exercise-induced bronchoconstriction despite otherwise wellcontrolled asthma, and for those in whom exercise-induced bronchoconstriction is the only manifestation of asthma, a rapidacting inhaled $\beta_{2}$-agonist (short- or long-acting), taken prior to exercise or to relieve symptoms that develop after exercise, is recommended [274]. A leukotriene modifier [76, 275] or cromone [276] are alternatives (Evidence A). Training and sufficient warm-up also reduce the incidence and severity of exercise-induced bronchoconstriction (Evidence B) [277, 278].

Step 2: Reliever medication plus a single controller. Treatment Steps 2-5 combine an as-needed reliever treatment with regular controller treatment. At Step 2, a low-dose inhaled glucocorticosteroid is recommended as the initial controller treatment for asthma patients of all ages (Evidence A; tables 4 and 5) $[147,271]$. Alternative controller medications include leukotriene modifiers (Evidence A) [73, 74, 80], particularly appropriate for patients who are unable or unwilling to use inhaled glucocorticosteroids or who experience intolerable side-effects, such as persistent hoarseness from inhaled glucocorticosteroid treatment, and possibly those with concomitant allergic rhinitis (Evidence C) [279, 280].

Other options are available, but not recommended, for routine use as initial or first-line controllers in Step 2. Sustained-release theophylline has only weak anti-inflammatory and controller efficacy (Evidence B) [110-112, 115, 116] and cromones (nedocromil sodium and sodium cromoglycate) have comparatively low efficacy (Evidence A) [281-284].

Step 3: Reliever medication plus one or two controllers. At Step 3, the recommended option for adolescents and adults is to combine a low dose of inhaled glucocorticosteroid with an inhaled long-acting $\beta_{2}$-agonist, either in a combination inhaler device or as separate components (Evidence A) [95-102]. Because of the additive effect of this combination, the low dose of glucocorticosteroid is usually sufficient and need only be increased if control is not achieved within 3-4 months with this regimen (Evidence $\mathrm{A})$. The long-acting $\beta_{2}$-agonist formoterol, which has a rapid onset of action whether given alone [285-288] or in combination inhaler with budesonide [289, 290], has been shown to be as effective as short-acting $\beta_{2^{-}}$ agonist in acute asthma exacerbation. However, its use as monotherapy as a reliever medication is strongly discouraged, since it must always be used in association with an inhaled glucocorticosteroid.
For all children, but particularly for those aged $\leqslant 5 \mathrm{yrs}$, combination therapy has been less well studied, and the addition of a long-acting $\beta_{2}$-agonist may not be as effective as increasing the dose of inhaled glucocorticosteroids in reducing exacerbations [182, 291, 292]. However, the interpretation of some studies is problematic, as not all children received concurrent inhaled glucocorticosteroids [182, 291].

If a combination inhaler containing formoterol and budesonide is selected, it may be used for both rescue and maintenance. This approach has been shown to result in reductions in exacerbations and improvements in asthma control in adults and adolescents at relatively low doses of treatment (Evidence A) [293-296]. Whether this approach can be employed with other combinations of controller and reliever requires further study.

Another option for both adults and children, but the one recommended for children [172], is to increase to a medium dose of inhaled glucocorticosteroids (Evidence A) [22, 54, 59, 60]. For patients of all ages on medium or high dose of inhaled glucocorticosteroid delivered by a pressurised metered-dose inhaler, use of a spacer device is recommended to improve delivery to the airways, reduce oropharyngeal side-effects and reduce systemic absorption (Evidence A) [62, 297, 298].

Another option at Step 3 is to combine a low-dose inhaled glucocorticosteroid with leukotriene modifiers (Evidence A) [79, 81-84, 86, 88-90]. Alternatively, the use of sustainedrelease theophylline given at a low dose may be considered (Evidence B) [115]. These options have not been fully studied in children aged $\leqslant 5$ yrs.

Step 4: Reliever medication plus two or more controllers. The selection of treatment at Step 4 depends on prior selections at Steps 2 and 3. However, the order in which additional medications should be added is based, as far as possible, upon evidence of their relative efficacy in clinical trials. Where possible, patients who are not controlled on Step 3 treatments should be referred to a health professional with expertise in the management of asthma for investigation of alternative diagnoses and/or causes of difficult-to-treat asthma.

The preferred treatment at Step 4 is to combine a medium or high dose of inhaled glucocorticosteroid with a long-acting inhaled $\beta_{2}$-agonist. However, in most patients, the increase from a medium to a high dose of inhaled glucocorticosteroid provides relatively little additional benefit (Evidence A) [22, $54,59,60,299$ ] and the high dose is recommended only on a trial basis for 3-6 months when control cannot be achieved with medium-dose inhaled glucocorticosteroid combined with a long-acting $\beta_{2}$-agonist and/or a third controller (e.g. leukotriene modifiers or sustained-release theophylline; Evidence B) [85, 116, 300]. At medium and high doses, twicedaily dosing is necessary for most but not all inhaled glucocorticosteroids (Evidence A) [301]. With budesonide, efficacy may be improved with more frequent dosing (four times daily; Evidence B) [302].

Leukotriene modifiers as add-on treatment to medium-highdose inhaled glucocorticosteroids provides benefit in some patients (Evidence A), but usually less than that achieved with the addition of a long-acting $\beta_{2}$-agonist (Evidence A) [81-85, 
303]. The addition of a low dose of sustained-release theophylline [116] to medium- or high-dose inhaled glucocorticosteroid and long-acting $\beta_{2}$-agonist may also provide benefit (Evidence B) [115].

Step 5: Reliever medication plus additional controller options. Addition of oral glucocorticosteroids to other controller medications may be effective (Evidence D) [304] but is associated with severe side-effects (Evidence A) [305] and should only be considered if the patient's asthma remains severely uncontrolled on Step 4 medications with daily limitation of activities and frequent exacerbations. Patients should be counselled about potential side-effects and all other alternative treatments must be considered.

Addition of anti-IgE treatment to other controller medications has been shown to improve control of allergic asthma when control has not been achieved on combinations of other controllers, including high doses of inhaled or oral glucocorticosteroids (Evidence A) [118-123].

\section{Monitoring to maintain control}

When asthma control has been achieved, ongoing monitoring is essential to maintain control and to establish the lowest step and dose of treatment necessary, which minimises the cost and maximises the safety of treatment. Conversely, asthma is a variable disease and treatment has to be adjusted periodically in response to loss of control, as indicated by worsening symptoms or the onset of an exacerbation. Asthma control should be monitored by the healthcare professional and preferably also by the patient at regular intervals. The frequency of healthcare visits and assessments depends upon the patient's initial clinical severity and the patient's training and confidence in playing a role in the ongoing control of his/ her asthma. Typically, patients are seen 1-3 months after the initial visit and every 3 months thereafter. After an exacerbation, follow-up should be offered within 2 weeks to 1 month (Evidence D).

\section{Duration and adjustments to treatment}

For most classes of controller medications, improvement begins within days of initiating treatment, but the full benefit may only be evident after 3-4 months [22, 306]. In severe and chronically undertreated disease, this can take even longer [307].

The reduced need for medication once control is achieved is not fully understood but may reflect the reversal of some of the consequences of long-term inflammation of the airways. Higher doses of anti-inflammatory medication may be required to achieve this benefit than to maintain it. Alternatively, the reduced need for medication might simply represent spontaneous improvement as part of the cyclical natural history of asthma. Rarely, asthma may go into remission, particularly in children aged $\leqslant 5$ yrs and during puberty. Whatever the explanation, the minimum controlling dose of treatment must be sought through a process of regular follow-up and staged dose reductions in all patients.

At other times, treatment may need to be increased either in response to loss of control or threat of loss of control (return of symptoms) or an acute exacerbation, which is defined as a more acute and severe loss of control that requires urgent treatment (an approach to exacerbations is provided in Component 4).

\section{Stepping down treatment when asthma is controlled}

There is little experimental data on the optimal timing, sequence, and magnitude of treatment reductions in asthma, and the approach will differ from patient to patient depending on the combination of medications and doses that were needed to achieve control. These changes should ideally be made by agreement between patient and healthcare professional, with full discussion of potential consequences, including reappearance of symptoms and increased risk of exacerbations.

Although further research on stepping down asthma treatment is needed, some recommendations can be made based on the current evidence.

1) When inhaled glucocorticosteroids alone are being used in medium-to-high doses, a 50\% reduction in dose should be attempted at 3-month intervals (Evidence B) [151, 308, 309].

2) Where control is achieved at a low dose of inhaled glucocorticosteroids alone, in most patients treatment may be switched to once-daily dosing (Evidence A) [310, 311].

3) When asthma is controlled with a combination of inhaled glucocorticosteroid and long-acting $\beta_{2}$-agonist, the preferred approach to is to begin by reducing the dose of inhaled glucocorticosteroid by $\sim 50 \%$ while continuing the long-acting $\beta_{2}$-agonist (Evidence B) [290]. If control is maintained, further reductions in the glucocorticosteroid dose should be attempted until a low dose is reached, when the long-acting $\beta_{2}$-agonist may be stopped (Evidence D). An alternative is to switch the combination treatment to once-daily dosing [312]. A second alternative is to discontinue the long-acting $\beta_{2}$-agonist at an earlier stage and substitute the combination treatment with inhaled glucocorticosteroid monotherapy at the same dose contained in the combination inhaler. However, for some patients these alternative approaches lead to loss of asthma control (Evidence B) [96, 290].

4) When asthma is controlled with inhaled glucocorticosteroids in combination with controllers other than long-acting $\beta_{2^{-}}$ agonists, the dose of inhaled glucocorticosteroid should be reduced by $50 \%$ until a low dose of inhaled glucocorticosteroid is reached, then the combination treatment stopped as described previously (Evidence D).

5) Controller treatment may be stopped if the patient's asthma remains controlled on the lowest dose of controller and no recurrence of symptoms occurs for $1 \mathrm{yr}$ (Evidence D).

\section{Stepping up treatment in response to loss of control}

Treatment has to be adjusted periodically in response to worsening control, which may be recognised by the minor recurrence or worsening of symptoms [313]. Treatment options are as follows.

1) Rapid-onset, short-acting or long-acting $\beta_{2}$-agonist bronchodilators. Repeated dosing with bronchodilators in this class provides temporary relief until the cause of the worsening symptoms passes. The need for repeated doses over more than 1-2 days signals the need for review and possible increase of controller therapy. 
2) Inhaled glucocorticosteroids. Temporarily doubling the dose of inhaled glucocorticosteroids has not been demonstrated to be effective and is no longer recommended (Evidence A) [312, 314]. A four-fold or greater increase has been demonstrated to be equivalent to a short course of oral glucocorticosteroids in adult patients with an acute deterioration (Evidence A) [313]. The higher dose should be maintained for 7-14 days but more research is needed in both adults and children to standardise the approach.

3) Combination of inhaled glucocorticosteroids and a rapid and long-acting $\beta_{2}$-agonist bronchodilator (e.g. formoterol) for combined relief and control. The use of the combination of a rapid and long-acting $\beta_{2}$-agonist and an inhaled glucocorticosteroid in a single inhaler both as a controller and reliever is effective in maintaining a high level of asthma control and reduces exacerbations requiring systemic glucocorticosteroids and hospitalisation [271, 294, 296, 315]. The benefit in preventing exacerbations appears to be the consequence of intervention at a very early stage of a threatened exacerbation, since studies involving doubling or quadrupling doses of combination treatment once deterioration is established (for $\geqslant 2$ days) show some benefit but results are inconsistent [313]. Combination therapy with budesonide and formoterol used both as maintenance and rescue has been shown to reduce asthma exacerbations in children aged $\geqslant 4$ yrs with moderateto-severe asthma [316].

4) The usual treatment for an acute exacerbation is a high dose of $\beta_{2}$-agonist and a burst of systemic glucocorticosteroids administered orally or intravenously (refer to Component 4 for more information).

Following treatment for an exacerbation of asthma, maintenance treatment can generally be resumed at previous levels, unless the exacerbation was associated with a gradual loss of control, suggesting chronic undertreatment. In this case, provided inhaler technique has been checked, a stepwise increase in treatment (either in dose or number of controllers) is indicated.

\section{Difficult-to-treat asthma}

Although the majority of asthma patients can obtain the targeted level of control (fig. 1), some patients will not do so, even with the best therapy [22]. Patients who do not reach an acceptable level of control at Step 4 (reliever medication plus two or more controllers) can be considered to have difficult-totreat asthma [317]. These patients may have an element of poor glucocorticosteroid responsiveness and require higher doses of inhaled glucocorticosteroids than are routinely used in patients whose asthma is easy to control. However, there is currently no evidence to support continuing these high doses of inhaled glucocorticosteroids beyond 6 months in the hope of achieving better control. Instead, dose optimisation should be pursued by stepping down to a dose that maintains the maximal level of control achieved on the higher dose.

Because very few patients are completely resistant to glucocorticosteroids, these medications remain a mainstay of therapy for difficult-to-treat asthma, while additional diagnostic and generalised therapeutic options can, and should, also be considered: confirm the diagnosis of asthma; investigate and confirm compliance with treatment; consider smoking, current or past, and encourage complete cessation; and investigate the presence of comorbidities that may aggravate asthma.

When these reasons for lack of treatment response have been considered and addressed, a compromise level of control may need to be accepted and discussed with the patient to avoid futile overtreatment (with its attendant cost and potential for adverse effects). The objective is then to minimise exacerbations and need for emergency medical interventions, while achieving as high a level of clinical control with as little disruption to activities and as few daily symptoms as possible. For these difficult-to-treat patients, frequent use of rescue medication is accepted, as is a degree of chronic lung function impairment.

Although lower levels of control are generally associated with an increased risk of exacerbations, not all patients with chronically impaired lung function, reduced activity levels, and daily symptoms have frequent exacerbations. In such patients, the lowest level of treatment that retains the benefits achieved at the higher doses of treatment should be employed. Reductions should be made cautiously and slowly, at intervals not more frequent than 3-6 months, as carryover of the effects of the higher dose may last for several months and make it difficult to assess the impact of the dose reduction (Evidence D). Referral to a physician with an interest in and/or special focus on asthma may be helpful and patients may benefit from phenotyping into categories such as allergic, aspirin-sensitive and/or eosinophilic asthma [318]. Patients categorised as allergic might benefit from anti-IgE therapy [118], and leukotriene modifiers can be helpful for patients determined to be aspirin sensitive (who are often eosinophilic as well) [79].

\section{Component 4: managing asthma exacerbations}

Exacerbations of asthma are episodes of progressive increase in shortness of breath, cough, wheezing or chest tightness, or some combination of these symptoms. Respiratory distress is common. The limitation of airflow observed during exacerbations (measured as PEF or FEV1) [319] is a more reliable indicator of the severity of the exacerbation than the degree of symptoms. However, symptoms are often sensitive indicators of the onset of an exacerbation because they usually precede the deterioration in peak flow rate [320]. Still, a minority of patients, and particularly males, perceive airflow limitation poorly and are at increased risk of near-fatal attacks of asthma.

Provision of assistance for patients experiencing exacerbations is essential in order to reduce morbidity and mortality. The organisation of such services will vary in different healthcare systems, but certain basic minimum requirements and treatment must be available [321, 322]: accessibility both during the day and at night, close objective monitoring (both clinical and using PEF), repetitive administration of rapid-acting inhaled bronchodilators, early introduction of systemic glucocorticosteroids and oxygen supplementation [319]. The aims of treatment are to relieve airflow obstruction and hypoxaemia as quickly as possible, and to plan the prevention of future relapses.

Patients at high risk of asthma-related death require closer attention and should be encouraged to seek urgent care early in the course of their exacerbations. These patients include 
those who: 1) have a history of near-fatal asthma requiring intubation and mechanical ventilation [323]; 2) have had a hospitalisation or emergency care visit for asthma in the previous year; 3) are currently using or have recently stopped using oral glucocorticosteroids; 4) are not currently using inhaled glucocorticosteroids [324]; 5) are overdependent on rapid-acting inhaled $\beta_{2}$-agonists, especially those who use more than one canister of salbutamol (or equivalent) monthly [325]; 6) have a history of psychiatric disease or psychosocial problems [326], including the use of sedatives [327]; and 7) have a history of noncompliance with an asthma medication plan.

Response to treatment may take time and patients should be closely monitored using clinical as well as objective measurements. The increased treatment should continue until measurements of lung function return to their previous best (ideally) or plateau, at which time a decision to admit or discharge can be made based upon these values. Patients who can be safely discharged will have responded within the first $2 \mathrm{~h}$, at which time decisions regarding patient disposition can be made.

The severity of the exacerbation determines the treatment administered. Indices of severity, particularly PEF (in patients aged $>5$ yrs) [306], pulse rate, respiratory rate and pulse oximetry [328] should be monitored during treatment.

\section{Management: community setting}

Most patients with severe asthma exacerbations should be treated in an acute care facility. Milder exacerbations, defined by a reduction in peak flow $<20 \%$, nocturnal awakening and increased use of short-acting $\beta_{2}$-agonists can usually be treated in a community setting. If the patient responds to the increase in inhaled bronchodilator treatment after the first few doses, referral to an acute care facility is not required but further management under the direction of a primary care physician may include the use of systemic glucocorticosteroids. Patient education and review of maintenance therapy should also be undertaken.

\section{Treatment}

Patients can be treated with multiple doses of short-acting bronchodilators delivered via an MDI, ideally with a spacer. This produces at least an equivalent improvement in lung function as the same dose delivered via nebuliser [297, 298]. At the clinic level, this route of delivery is the most cost effective [329], provided patients are able to use an MDI. No additional medication is necessary if the rapid-acting inhaled $\beta_{2}$-agonist produces a complete response (PEF returns to $>80 \%$ predicted or personal best) and the response lasts $3-4 \mathrm{~h}$.

Glucocorticosteroids. Oral glucocorticosteroids $\left(0.5-1 \mathrm{mg} \cdot \mathrm{kg}^{-1}\right.$ of prednisolone or equivalent during a 24 -h period) should be used to treat exacerbations, especially if they develop after instituting the other short-term treatment options recommended for loss of control (see Stepping up treatment in response to loss of control in Component 3). If patients fail to respond to bronchodilator therapy, as indicated by persistent airflow obstruction, prompt transfer to an acute care setting is recommended, especially if they are in a highrisk group.

\section{Management: acute care setting}

Severe exacerbations of asthma are life-threatening medical emergencies, treatment of which is often most safely undertaken in an emergency department. Figure 2 illustrates the approach to acute care-based management of exacerbations.

\section{Assessment}

A brief history and physical examination pertinent to the exacerbation should be conducted concurrently with the prompt initiation of therapy. The history should include: severity and duration of symptoms, including exercise limitation and sleep disturbance; all current medications, including dose (and device) prescribed, dose usually taken, dose taken in response to the deterioration, and the patient's response (or lack thereof) to this therapy; time of onset and cause of the present exacerbation; and risk factors for asthma-related death

The physical examination should assess exacerbation severity by evaluating the patient's ability to complete a sentence, pulse rate, respiratory rate, use of accessory muscles and other signs detailed in figure 2. Any complicating factors should be identified (e.g. pneumonia, atelectasis, pneumothorax or pneumomediastinum).

Functional assessments such as PEF or FEV1 and arterial oxygen saturation measurements are strongly recommended, as physical examination alone may not fully indicate the severity of the exacerbation, particularly the degree of hypoxaemia [330, 331]. Without unduly delaying treatment, a baseline PEF or FEV1 measurement should be made before treatment is initiated. Subsequent measurements should be made at intervals until a clear response to treatment has occurred.

Oxygen saturation should be closely monitored, preferably by pulse oximetry. This is especially useful in children because objective measurements of lung function may be difficult. Oxygen saturation in children should normally be $>95 \%$, and oxygen saturation $<92 \%$ is a good predictor of the need for hospitalisation (Evidence C) [328]. Arterial blood gas measurements are advised for patients with a PEF of $30-50 \%$ pred, those who do not respond to initial treatment, or when there is concern regarding deterioration [332]. The patient should continue on supplemental oxygen while the measurement is made. An arterial oxygen tension $<60 \mathrm{mmHg}(8 \mathrm{kPa})$ and a normal or increased arterial carbon dioxide tension (especially $>45 \mathrm{mmHg} ; 6 \mathrm{kPa}$ ) indicates the presence of respiratory failure.

A chest radiograph is not routinely required in either children or adults, unless alternative pathology is suspected on clinical grounds [332, 333]

\section{Treatment}

The following treatments are usually administered concurrently [334].

Oxygen. To achieve arterial oxygen saturation of $\geqslant 90 \%(\geqslant 95 \%$ in children), oxygen should be administered by nasal cannulae, by mask or, rarely, by head box in some infants. Arterial carbon dioxide tension may worsen in some patients on $100 \%$ oxygen, especially those with more severe airflow obstruction 


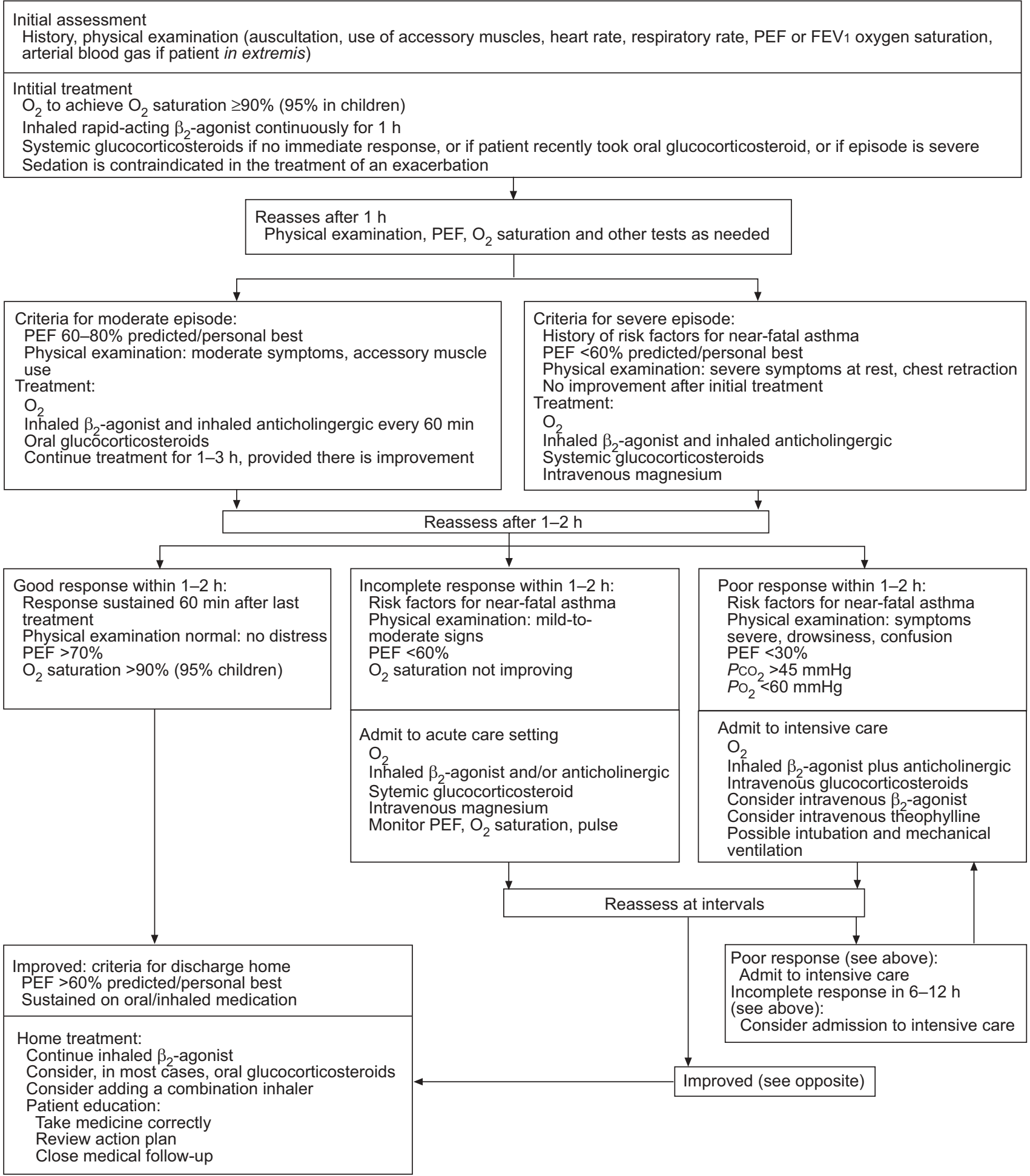

FIGURE 2. Management of asthma exacerbations in the acute care setting. PEF: peak expiratory flow; FEV1: forced expiratory volume in one second; $P \mathrm{CO}_{2}$ : carbon dioxide tension; $\mathrm{PO}_{2}$ : oxygen tension. $1 \mathrm{mmHg}=0.133 \mathrm{kPa}$.

[335]. Oxygen therapy should be titrated against pulse oximetry to maintain satisfactory oxygen saturation [336].

Rapid-acting inhaled $\beta_{2}$-agonists. Rapid-acting inhaled $\beta_{2}$-agonists should be administered at regular intervals (Evidence A) [337-339]. Although most rapid-acting $\beta_{2}$-agonists have a short duration of effect, the long-acting bronchodilator formoterol, which has both a rapid onset of action and a long duration of effect, has been shown to be equally effective without increasing side-effects, though it is considerably more expensive [285]. Studies of intermittent versus continuous nebulised short-acting $\beta_{2}$-agonists in acute asthma provide conflicting 
results [340,341]. Therefore, a reasonable approach to inhaled therapy in exacerbations would be the initial use of continuous therapy, followed by intermittent on-demand therapy for hospitalised patients. There is no evidence to support the routine use of intravenous $\beta_{2}$-agonists in patients with severe asthma exacerbations [342].

Epinephrine. A subcutaneous or intramuscular injection of epinephrine may be indicated for acute treatment of anaphylaxis and angioedema, but is not routinely indicated during asthma exacerbations.

Additional bronchodilators. A combination of nebulised $\beta_{2}-$ agonist with an anticholinergic (ipratropium bromide) may produce better bronchodilation than either drug alone (Evidence B) [343] and should be administered before methylxanthines are considered. Combination $\beta_{2}$-agonist plus anticholinergic therapy is associated with lower hospitalisation rates (Evidence A) [329, 344, 345] and greater improvement in PEF and FEV1 (Evidence B) [345]. Similar data have been reported in the paediatric literature (Evidence A) [329]. However, once hospitalised, the addition of nebulised ipratropium bromide to nebulised $\beta_{2}$-agonist and systemic glucocorticosteroids appears to confer no extra benefit [346].

In view of the effectiveness and relative safety of rapid-acting $\beta_{2}$-agonists, theophylline has a minimal role in the management of acute asthma [347]. Benefit as add-on treatment has been shown in children with near-fatal asthma but not in adults [348].

Systemic glucocorticosteroids. Systemic glucocorticosteroids speed resolution of exacerbations and should be utilised in the all but the mildest exacerbations (Evidence A) [349, 350], especially if the initial rapid-acting inhaled $\beta_{2}$-agonist therapy fails to achieve lasting improvement; the exacerbation develops even though the patient was already taking oral glucocorticosteroids; and previous exacerbations required oral glucocorticosteroids.

Oral glucocorticosteroids are usually as effective as those administered intravenously and are preferred because this route of delivery is less invasive and less expensive [351, 352]. In patients discharged from the emergency department, intramuscular administration may be helpful [353], especially if there are concerns about compliance with oral therapy. Oral glucocorticosteroids require $\geqslant 4 \mathrm{~h}$ to produce clinical improvement. Daily doses of systemic glucocorticosteroids equivalent to $60-80 \mathrm{mg}$ methylprednisolone as a single dose, or 300-400 mg hydrocortisone in divided doses, are adequate for hospitalised patients, and $40 \mathrm{mg}$ methylprednisolone or $200 \mathrm{mg}$ hydrocortisone is probably adequate in most cases (Evidence B) [349, 354]. An oral glucocorticosteroid dose of $1 \mathrm{mg} \cdot \mathrm{kg}^{-1}$ daily is adequate for treatment of exacerbations in children with mild persistent asthma [355]. A 7-day course in adults has been found to be as effective as a 14-day course [356], and a course of duration 35 days is usually considered appropriate in children (Evidence B). Current evidence suggests that there is no benefit in tapering the dose of oral glucocorticosteroids, either in the short term [357] or over several weeks (Evidence B) [358].

Inhaled glucocorticosteroids. Inhaled glucocorticosteroids are effective as part of therapy for asthma exacerbations. In one study, the combination of high-dose inhaled glucocorticosteroids and salbutamol in acute asthma provided greater bronchodilation than salbutamol alone (Evidence B) [359], and conferred greater benefit than the addition of systemic glucocorticosteroids across all parameters, including hospitalisations, especially for patients with more severe attacks [360].

Inhaled glucocorticosteroids can be as effective as oral glucocorticosteroids at preventing relapses [361, 362]. Patients discharged from the emergency department on prednisone and inhaled budesonide have a lower rate of relapse than those on prednisone alone (Evidence B) [350]. A high dose of inhaled glucocorticosteroid ( $2.4 \mathrm{mg}$ budesonide daily in four divided doses) achieves a relapse rate similar to $40 \mathrm{mg}$ oral prednisone daily (Evidence A) [363]. Cost is a significant factor in the use of such high doses of inhaled glucocorticosteroids and further studies are required to document their potential benefits, especially cost effectiveness, in acute asthma [364].

Magnesium. Intravenous magnesium sulfate (usually given as a single 2-g infusion over $20 \mathrm{~min}$ ) reduces hospital admission rates in adults and older children with severe bronchospasm who fail to improve promptly to bronchodilators (Evidence A) $[365,366]$. Nebulised salbutamol administered in isotonic magnesium sulfate provides greater benefit than if it is delivered in normal saline (Evidence A) [367, 368].

Helium oxygen therapy. A systematic survey of studies of a combination of helium and oxygen, compared with helium alone, suggests there is no consistent benefit. It might be considered for patients who do not respond to standard therapy [369].

Sedatives. Sedation should be strictly avoided during exacerbations of asthma because of the respiratory depressant effect of anxiolytic and hypnotic drugs [327, 370].

\section{Criteria for discharge from the emergency department versus hospitalisation}

Criteria for determining whether a patient should be discharged from the emergency department or admitted to the hospital have been succinctly reviewed and stratified based on consensus [371]. Patients with a pre-treatment FEV1 or PEF $<25 \%$ pred or personal best, or those with a post-treatment FEV1 or PEF $<40 \%$ pred or personal best, usually require hospitalisation. Patients with post-treatment lung function of $40-60 \%$ pred may be discharged, provided that adequate follow-up is available in the community and compliance is assured. Patients with post-treatment lung function $\geqslant 60 \%$ pred can be discharged.

Management of acute asthma in the intensive care unit is beyond the scope of the present document and readers are referred to recent comprehensive reviews [372].

The following points refer to patients discharged from the emergency department. 1) At a minimum, a 7-day course of oral glucocorticosteroids for adults and a shorter course (35 days) for children should be prescribed, along with continuation of bronchodilator therapy. 2) The bronchodilator can be used on an as-needed basis, based on both symptomatic and objective improvement, until the patient returns to his or 
her pre-exacerbation use of rapid-acting inhaled $\beta_{2}$-agonists. 3) Ipratropium bromide is unlikely to provide additional benefit beyond the acute phase and may be quickly discontinued. 4) Patients should initiate or continue inhaled glucocorticosteroids. 5) The patient's inhaler technique and use of peak flow meter to monitor therapy at home should be reviewed. Patients discharged from the emergency department with a peak flow meter and action plan have a better response than patients discharged without these resources [199]. 6) The factors that precipitated the exacerbation should be identified and strategies for their future avoidance implemented. 7) The patient's response to the exacerbation should be evaluated. The action plan should be reviewed and written guidance provided. 8) Use of controller therapy during the exacerbation should be reviewed: whether this therapy was increased promptly, by how much and, if appropriate, why oral glucocorticosteroids were not added. Consideration should be given to providing a short course of oral glucocorticosteroids to be on hand for subsequent exacerbations. 9) The patient or family should be instructed to contact the primary healthcare professional or asthma specialist within $24 \mathrm{~h}$ of discharge. A follow-up appointment with the patient's usual primary care professional or asthma specialist should be made within a few days of discharge to assure that treatment is continued until baseline control parameters, including personal best lung function, are reached. Prospective data indicate that patients discharged from the emergency department for follow-up with specialist care do better than patients returned to routine care [373].

An exacerbation severe enough to require hospitalisation may reflect a failure of the patient's self-management plan. Healthcare providers should take the opportunity to review patient understanding of the causes of asthma exacerbations, avoidance of factors that may cause exacerbations (including, where relevant, smoking cessation), the purposes and correct uses of treatment, and the actions to be taken to respond to worsening symptoms or peak flow values (Evidence A) [374].

Referral to an asthma specialist and or to an asthma education programme should be considered for hospitalised patients, as well as those who are discharged from the emergency department. Following discharge from continuous supervision, the patient should be reviewed by the family healthcare professional or asthma specialist regularly over the subsequent weeks until personal best lung function is reached.

\section{Component 5: special considerations}

Special considerations apply in managing asthma in relation to pregnancy; surgery; rhinitis, sinusitis, and nasal polyps; occupational asthma; respiratory infections; gastroesophageal reflux; aspirin-induced asthma (AIA); and anaphylaxis.

\section{Pregnancy}

During pregnancy, the control of asthma may change and patients require close follow-up. Although concern about the use of medications in pregnancy is legitimate, the impact of poorly controlled asthma is probably more significant as a cause of fetal viability, perinatal mortality, prematurity and low birth weight $[375,376]$. However, if managed well, the perinatal prognosis for children born to females with asthma is comparable to that for children born to females without asthma [377]. For this reason, using medications to obtain optimal control of asthma is justified even when their safety in pregnancy has not been unequivocally proven, and the goals of asthma treatment are the same as for non-pregnant females. Acute exacerbations should be treated aggressively in order to avoid fetal hypoxia. For most medications used to treat asthma there is little evidence to suggest an increased risk to the fetus [378]. A good patient-healthcare professional relationship, along with independent printed material, such as the statement from the National Asthma Education and Prevention Program (USA) on the treatment of asthma during pregnancy [379], will provide important additional reassurance [380, 381].

\section{Surgery}

Airway hyperresponsiveness, airflow limitation and mucus hypersecretion predispose patients with asthma to intraoperative and post-operative respiratory complications. The likelihood of these complications depends on the severity of asthma at the time of surgery, the type of surgery (thoracic and upper abdominal surgeries pose the greatest risks) and type of anaesthesia (general anaesthesia with endotracheal intubation carries the greatest risk). These variables need to be assessed prior to surgery and pulmonary function should be measured. If possible, this evaluation should be undertaken several days before surgery to allow time for additional treatment. In particular, if the patient's FEV1 is $<80 \%$ of their personal best, a brief course of oral glucocorticosteroids should be considered to reduce airflow limitation (Evidence C) [382, 383]. Furthermore, patients who have received systemic glucocorticosteroids within the previous 6 months should have systemic coverage during the surgical period (100 mg hydrocortisone every $8 \mathrm{~h}$ intravenously). This should be rapidly reduced $24 \mathrm{~h}$ following surgery, as prolonged systemic glucocorticosteroid therapy may inhibit wound healing (Evidence C) [384].

\section{Rhinitis, sinusitis and nasal polyps}

Upper airway diseases can influence lower airway function in some patients with asthma. Although the mechanisms behind this relationship have not been established, inflammation probably plays a similarly critical role in the pathogenesis of rhinitis, sinusitis and nasal polyps, as in asthma. The Allergic Rhinitis and its Impact on Asthma (ARIA) initiative recommends that the presence of asthma must be considered in all patients with rhinitis, and that in planning treatment both should be considered together $[385,386]$.

\section{Occupational asthma}

Once a diagnosis of occupational asthma is established, complete avoidance of the relevant exposure is ideally an important component of management [387-389]. Occupational asthma may persist even several years after removal from exposure to the causative agent, especially when the patient has had symptoms for a long time before cessation of exposure $[390,391]$. Continued exposure may lead to increasingly severe and potentially fatal asthma exacerbations [392], a lower probability of subsequent remission and, ultimately, permanently impaired lung function [393]. Pharmacological therapy for occupational asthma is identical to therapy for other forms of asthma, but it is not a substitute for adequate avoidance. The British Occupational Health Research Foundation Guidelines for the prevention, identification and management of occupational asthma are available [394]. 


\section{Respiratory infections}

Respiratory infections have an important relationship to asthma as they provoke wheezing and increased symptoms in many patients [395]. Epidemiological studies have found that infectious microorganisms associated with increased asthma symptoms are often respiratory viruses [396] but seldom bacteria [397]. Respiratory syncytial virus is the most common cause of wheezing in infancy [239], while rhinoviruses (which cause the common cold) are the principal triggers of wheezing and worsening of asthma in older children and adults [398]. Other respiratory viruses, such as parainfluenza, influenza, adenovirus and coronavirus, are also associated with increased wheezing and asthma symptoms [399]. Treatment of an infectious exacerbation follows the same principles as treatment of other asthma exacerbations. Because increased asthma symptoms can often persist for weeks after the infection is cleared, anti-inflammatory treatment should be continued for this full period to ensure adequate control.

\section{Gastro-oesophageal reflux}

The relationship of increased asthma symptoms, particularly at night, to gastroesophageal reflux remains uncertain, although this condition is nearly three times as prevalent in patients with asthma compared with the general population [400, 401]. Some of these patients also have a hiatal hernia; furthermore, theophylline and oral $\beta_{2}$-agonists may increase the likelihood of symptoms by relaxing the lower oesophageal ring. Treatment with anti-acid therapies $\left(\mathrm{H}_{2}\right.$ antagonists or proton pump inhibitors) does not improve asthma control.

\section{Aspirin-induced asthma}

A small minority of adults with asthma, but rarely children with asthma, suffer from asthma exacerbations in response to aspirin and other nonsteroidal anti-inflammatory drugs (NSAIDs). This syndrome is more common in severe asthma [402]. Once aspirin or NSAID hypersensitivity develops, it is present for life. Patients with AIA should avoid aspirin, products containing it, other analgesics that inhibit cyclooxygenase (COX)-1, and often also hydrocortisone hemisuccinate [403]. Glucocorticosteroids continue to be the mainstay of asthma therapy but leukotriene modifiers may also be useful for additional control of the underlying disease (Evidence B) $[402,404]$. COX-2 inhibitors do not provoke AIA and may be indicated as analgesic or anti-inflammatory treatments if there are no cardiovascular contraindications.

\section{IMPLEMENTATION OF ASTHMA GUIDELINES IN HEALTH SYSTEMS \\ Introduction}

Guidelines are designed to ensure that all members of a patient's healthcare team are aware of the goals of treatment and of the different ways of achieving these goals. They help set standards of clinical care, may serve as a basis for audit and payment, and act as a starting point for the education of health professionals and patients. However, in order to effect changes in medical practice and consequent improvements in patient outcomes, evidence-based guidelines must be implemented and disseminated at national and local levels. Dissemination involves educating clinicians to improve their awareness, knowledge and understanding of guideline recommendations. It is one part of implementation, which involves the translation of evidence-based asthma guidelines into real-life practice with improvement of health outcomes for the patient. Implementation remains a difficult problem worldwide. Barriers to implementation range from poor infrastructure, which hampers delivery of medicines to remote parts of a country, to cultural factors that make patients reluctant to use recommended medications (e.g. inhaled preparations) and lack of physician use of guidelines. An important barrier to the successful translation of asthma guidelines into clinical practice is access to available and affordable medication, especially for patients in less developed economies where the cost of treatment is high in comparison to income and assets.

\section{Guideline implementation strategies}

Implementation of asthma guidelines should begin with the setting of goals and development of strategies for asthma care through collaboration among diverse professional groups including both primary and secondary healthcare professionals, public health officials, patients, asthma advocacy groups and the general public. Goals and implementation strategies will vary from country to country, and within countries, for reasons of economics, culture and environment.

The next step is adaptation of guidelines on asthma management for local use by teams of local primary and secondary care health professionals. Many low- and middle-income countries do not consider asthma a high-priority health concern because other, more common, respiratory diseases, such as tuberculosis and pneumonia, are of greater public health importance [405]. Therefore, practical asthma guidelines for implementation in low-income countries should have a simple algorithm for separating noninfectious from infectious respiratory illnesses; simple objective measurements for diagnosis and management such as peak flow variability [406]; available, affordable and low-risk medications recommended for asthma control; a simple regime for recognising severe asthma; and simple diagnosis and management approaches relevant to the facilities and limited resources available. Next, adapted guidelines must be widely disseminated in multiple venues and using multiple formats.

Cost is recognised as an important barrier to the delivery of optimal evidence-based healthcare in almost every country, although its impact on patients' access to treatments varies widely both between and within countries. At the country or local level, health authorities make resource availability and allocation decisions affecting populations of asthma patients by considering the balance and trade-offs between costs and clinical outcomes (benefits and harms), often in relation to competing public health and medical needs. Treatment costs must also be explicitly considered at each consultation between healthcare provider and patient to assure that cost does not present a barrier to achieving asthma control. Therefore, those involved in the adaptation and implementation of asthma guidelines require an understanding of the cost and cost effectiveness of various management recommendations in asthma care.

Public health strategies involving a broad coalition of stakeholders in asthma care, including medical societies, healthcare professionals, patient support groups, government and the private sector, have been implemented in Australia 
(Australian National Asthma Campaign) [407], Finland [408], and the USA (National Asthma Education and Prevention Program) [229].

\section{GINA dissemination and implementation resources}

Educational materials based on this Global Strategy for Asthma Management and Prevention are available in several forms, including a pocket guide for healthcare professionals and one for patients and families. These are available on the GINA website [3]. GINA is a partner organisation of the Global Alliance Against Chronic Respiratory Diseases (GARD): a World Health Organization initiative [409].

\section{REFERENCES}

1 Global Strategy for Asthma Management and Prevention. Global Initiative for Asthma (GINA), 2002. Available from www.ginasthma.org Date last updated, 2002.

2 Global Strategy for Asthma Management and Prevention. Global Initiative for Asthma (GINA), 2006. Available from www.ginasthma.org Date last updated, 2006.

3 Global Initiative for Asthma (GINA). Documents available from www.ginasthma.org.

4 Reddel H, Ware S, Marks G, Salome C, Jenkins C, Woolcock A. Differences between asthma exacerbations and poor asthma control. Lancet 1999; 353: 364-369.

5 Beasley R The Global Burden of Asthma Report; Global Initiative for Asthma (GINA) www.ginasthma.org/ ReportItem.asp? $11=2 \& 12=2 \&$ intId $=94$ Date last updated: 2004.

6 Masoli M, Fabian D, Holt S, Beasley R. The global burden of asthma: executive summary of the GINA Dissemination Committee report. Allergy 2004; 59: 469-478.

7 Urrutia I, Aguirre U, Sunyer J, et al. Changes in the prevalence of asthma in the spanish cohort of the European Community Respiratory Health Survey (ECRHS-II). Arch Bronconeumol 2007; 43: 425-430.

8 Carvajal-Uruena I, Garcia-Marcos L, Busquets-Monge R, et al. [Geographic variation in the prevalence of asthma symptoms in Spanish children and adolescents. International Study of Asthma and Allergies in Childhood (ISAAC) Phase 3, Spain]. Arch Bronconeumol 2005; 41: 659-666.

9 Yan DC, Ou LS, Tsai TL, Wu WF, Huang JL. Prevalence and severity of symptoms of asthma, rhinitis, and eczema in 13- to 14-year-old children in Taipei, Taiwan. Ann Allergy Asthma Immunol 2005; 95: 579-585.

10 Garcia-Marcos L, Quiros AB, Hernandez GG, et al. Stabilization of asthma prevalence among adolescents and increase among schoolchildren (ISAAC phases I and III) in Spain. Allergy 2004; 59: 1301-1307.

11 Asher MI, Montefort S, Bjorksten B, et al. Worldwide time trends in the prevalence of symptoms of asthma, allergic rhinoconjunctivitis, and eczema in childhood: ISAAC Phases One and Three repeat multicountry cross-sectional surveys. Lancet 2006; 268: 733-743.

12 Pachter LM, Weller SC, Baer RD, et al. Variation in asthma beliefs and practices among mainland Puerto Ricans, Mexican-Americans, Mexicans, and Guatemalans. J Asthma 2002; 39: 119-134.
13 Accordini S, Bugiani M, Arossa W, et al. Poor control increases the economic cost of asthma. A multicentre population-based study. Int Arch Allergy Immunol 2006; 141: 189-198.

14 Briggs AH, Bousquet J, Wallace MV, et al. Cost-effectiveness of asthma control: an economic appraisal of the GOAL study. Allergy 2006; 61: 531-536.

15 Sullivan SD, Rasouliyan L, Russo PA, Kamath T, Chipps BE. Extent, patterns, and burden of uncontrolled disease in severe or difficult-to-treat asthma. Allergy 2007; 62: 126-133.

16 Holgate ST. Genetic and environmental interaction in allergy and asthma. J Allergy Clin Immunol 1999; 104: 1139-1146.

17 Ober C. Perspectives on the past decade of asthma genetics. J Allergy Clin Immunol 2005; 116: 274-278.

18 Zambrano JC, Carper HT, Rakes GP, et al. Experimental rhinovirus challenges in adults with mild asthma: response to infection in relation to IgE. J Allergy Clin Immunol 2003; 111: 1008-1016.

19 Chalmers GW, Macleod KJ, Little SA, Thomson LJ, McSharry CP, Thomson NC. Influence of cigarette smoking on inhaled corticosteroid treatment in mild asthma. Thorax 2002; 57: 226-230.

20 Lazarus SC, Chinchilli VM, Rollings NJ, et al. Smoking affects response to inhaled corticosteroids or leukotriene receptor antagonists in asthma. Am J Respir Crit Care Med 2007; 175: 783-790.

21 Chaudhuri R, Livingston E, McMahon AD, Thomson L, Borland W, Thomson NC. Cigarette smoking impairs the therapeutic response to oral corticosteroids in chronic asthma. Am J Respir Crit Care Med 2003; 168: 1308-1311.

22 Bateman ED, Boushey HA, Bousquet J, et al. Can guideline-defined asthma control be achieved? The Gaining Optimal Asthma Control study. Am J Respir Crit Care Med 2004; 170: 836-844.

23 Levy ML, Fletcher M, Price DB, Hausen T, Halbert RJ, Yawn BP. International Primary Care Respiratory Group (IPCRG) Guidelines: diagnosis of respiratory diseases in primary care. Prim Care Respir J 2006; 15: 20-34.

24 Yssel H, Abbal C, Pene J, Bousquet J. The role of IgE in asthma. Clin Exp Allergy 1998; 28: Suppl. 5, 104-109.

25 Corrao WM, Braman SS, Irwin RS. Chronic cough as the sole presenting manifestation of bronchial asthma. $N$ Engl J Med 1979; 300: 633-637.

26 Killian KJ, Watson R, Otis J, St Amand TA, O’Byrne PM. Symptom perception during acute bronchoconstriction. Am J Respir Crit Care Med 2000; 162: 490-496.

27 Standardized lung function testing. Official statement of the European Respiratory Society. Eur Respir J Suppl 1993; 16: $1-100$.

28 Standardization of Spirometry, 1994 Update. American Thoracic Society. Am J Respir Crit Care Med 1995; 152: 1107-1136.

29 Pellegrino R, Viegi G, Brusasco V, et al. Interpretative strategies for lung function tests. Eur Respir J 2005; 26: 948-968.

30 Sawyer G, Kemp T, Shaw R, et al. Biologic pollution in infant bedding in New Zealand: high allergen exposure during a vulnerable period. J Allergy Clin Immunol 1998; 102: 765-770. 
31 Eid N, Yandell B, Howell L, Eddy M, Sheikh S. Can peak expiratory flow predict airflow obstruction in children with asthma? Pediatrics 2000; 105: 354-358.

32 Reddel HK, Marks GB, Jenkins CR. When can personal best peak flow be determined for asthma action plans? Thorax 2004; 59: 922-924.

33 Cockcroft DW. Bronchoprovocation methods: direct challenges. Clin Rev Allergy Immunol 2003; 24: 19-26.

34 Mok Q, Piesowicz AT. Foreign body aspiration mimicking asthma. Intensive Care Med 1993; 19: 240-241.

35 Place R, Morrison A, Arce E. Vocal cord dysfunction. J Adolesc Health 2000; 27: 125-129.

36 Price DB, Tinkelman DG, Halbert RJ, et al. Symptombased questionnaire for identifying COPD in smokers. Respiration 2006; 73: 285-295.

37 Tinkelman DG, Price DB, Nordyke RJ, et al. Symptombased questionnaire for differentiating COPD and asthma. Respiration 2006; 73: 296-305.

38 Green RH, Brightling CE, McKenna S, et al. Asthma exacerbations and sputum eosinophil counts: a randomised controlled trial. Lancet 2002; 360: 1715-1721.

39 Horvath I, Barnes PJ. Exhaled monoxides in asymptomatic atopic subjects. Clin Exp Allergy 1999; 29: 12761280.

40 Kharitonov S, Alving K, Barnes PJ. Exhaled and nasal nitric oxide measurements: recommendations. The European Respiratory Society Task Force. Eur Respir J 1997; 10: 1683-1693.

41 Pizzichini MM, Popov TA, Efthimiadis A, et al. Spontaneous and induced sputum to measure indices of airway inflammation in asthma. Am J Respir Crit Care Med 1996; 154: 866-869.

42 Smith AD, Taylor DR. Is exhaled nitric oxide measurement a useful clinical test in asthma? Curr Opin Allergy Clin Immunol 2005; 5: 49-56.

43 Measurement of health-related quality of life. Adult asthma. www.qoltech.co.uk/asthma1.htm Date last updated: November, 2006. Date last accessed: July 15, 2007.

44 Juniper EF, Buist AS, Cox FM, Ferrie PJ, King DR. Validation of a standardized version of the Asthma Quality of Life Questionnaire. Chest 1999; 115: 1265-1270.

45 Liu AH, Zeiger R, Sorkness C, et al. Development and cross-sectional validation of the Childhood Asthma Control Test. J Allergy Clin Immunol 2007; 119: 817-825.

46 American Lung Association. Take the asthma control test and share the results with your doctor. www.asthmacontrol.com Date last updated: January 8, 2001. Date last accessed: July 15, 2007.

47 Nathan RA, Sorkness CA, Kosinski M, et al. Development of the asthma control test: a survey for assessing asthma control. J Allergy Clin Immunol 2004; 113: 59-65.

48 ATAQ Instrument. Asthma Therapy Assessment Questionnaire. www.ATAQInstrument.com Date last updated: 2006. Date last accessed, July 15, 2007.

49 Vollmer WM, Markson LE, O'Connor E, et al. Association of asthma control with health care utilization and quality of life. Am J Respir Crit Care Med 1999; 160: 1647-1652.

50 Boulet LP, Boulet V, Milot J. How should we quantify asthma control? A proposal. Chest 2002; 122: 2217-2223.
51 Juniper EF, Kline PA, Vanzieleghem MA, Ramsdale EH, O'Byrne PM, Hargreave FE. Effect of long-term treatment with an inhaled corticosteroid (budesonide) on airway hyperresponsiveness and clinical asthma in nonsteroiddependent asthmatics. Am Rev Respir Dis 1990; 142: 832-836.

52 The Childhood Asthma Managment Program Research Group. Long term effects of budesonide or nedocromil in children with asthma. N Engl J Med 2000; 343: 1054-1063.

53 Jeffery PK, Godfrey RW, Adelroth E, Nelson F, Rogers A, Johansson SA. Effects of treatment on airway inflammation and thickening of basement membrane reticular collagen in asthma. A quantitative light and electron microscopic study. Am Rev Respir Dis 1992; 145: 890-899.

54 Pauwels RA, Lofdahl CG, Postma DS, et al. Effect of inhaled formoterol and budesonide on exacerbations of asthma. Formoterol and Corticosteroids Establishing Therapy (FACET) International Study Group. N Engl J Med 1997; 337: 1405-1411.

55 Suissa S, Ernst P, Benayoun S, Baltzan M, Cai B. Lowdose inhaled corticosteroids and the prevention of death from asthma. N Engl J Med 2000; 343: 332-336.

56 Jayasiri B, Perera C. Successful withdrawal of inhaled corticosteroids in childhood asthma. Respirology 2005; 10: 385-388.

57 Waalkens HJ, Van Essen-Zandvliet EE, Hughes MD, et al. Cessation of long-term treatment with inhaled corticosteroid (budesonide) in children with asthma results in deterioration. The Dutch CNSLD Study Group. Am Rev Respir Dis 1993; 148: 1252-1257.

58 National Asthma Education and Prevention Program. Guidelines for the diagnosis and management of asthma. Bethesda, National Heart, Lung, and Blood Institute, National Institutes of Health, 1997.

59 Powell H, Gibson PG. Inhaled corticosteroid doses in asthma: an evidence-based approach. Med J Aust 2003; 178: 223-225.

60 Szefler SJ, Martin RJ, King TS, et al. Significant variability in response to inhaled corticosteroids for persistent asthma. J Allergy Clin Immunol 2002; 109: 410-418.

61 Mak VH, Melchor R, Spiro SG. Easy bruising as a sideeffect of inhaled corticosteroids. Eur Respir J 1992; 5: 10681074.

62 Brown PH, Greening AP, Crompton GK. Large volume spacer devices and the influence of high dose beclomethasone dipropionate on hypothalamo-pituitary-adrenal axis function. Thorax 1993; 48: 233-238.

63 Lipworth BJ. Systemic adverse effects of inhaled corticosteroid therapy: a systematic review and meta-analysis. Arch Intern Med 1999; 159: 941-955.

64 Lung Health Study Research Group. Effect of inhaled triamcinolone on the decline in pulmonary function in chronic obstructive pulmonary disease. $N$ Engl J Med 2000; 343: 1902-1909.

65 Pauwels RA, Yernault JC, Demedts MG, Geusens P. Safety and efficacy of fluticasone and beclomethasone in moderate to severe asthma. Belgian Multicenter Study Group. Am J Respir Crit Care Med 1998; 157: 827-832.

66 Ernst P, Baltzan M, Deschenes J, Suissa S. Low-dose inhaled and nasal corticosteroid use and the risk of cataracts. Eur Respir J 2006; 27: 1168-1174. 
67 Cumming RG, Mitchell P, Leeder SR. Use of inhaled corticosteroids and the risk of cataracts. $N$ Engl J Med 1997; 337: 8-14.

68 Garbe E, LeLorier J, Boivin JF, Suissa S. Inhaled and nasal glucocorticoids and the risks of ocular hypertension or open-angle glaucoma. JAMA 1997; 277: 722-727.

69 Agertoft L, Larsen FE, Pedersen S. Posterior subcapsular cataracts, bruises and hoarseness in children with asthma receiving long-term treatment with inhaled budesonide. Eur Respir J 1998; 12: 130-135.

70 Simons FE, Persaud MP, Gillespie CA, Cheang M, Shuckett EP. Absence of posterior subcapsular cataracts in young patients treated with inhaled glucocorticoids. Lancet 1993; 342: 776-778.

71 Toogood JH, Markov AE, Baskerville J, Dyson C. Association of ocular cataracts with inhaled and oral steroid therapy during long-term treatment of asthma. $J$ Allergy Clin Immunol 1993; 91: 571-579.

72 Dicpinigaitis PV, Dobkin JB, Reichel J. Antitussive effect of the leukotriene receptor antagonist zafirlukast in subjects with cough-variant asthma. J Asthma 2002; 39: 291-297.

73 Barnes NC, Miller CJ. Effect of leukotriene receptor antagonist therapy on the risk of asthma exacerbations in patients with mild to moderate asthma: an integrated analysis of zafirlukast trials. Thorax 2000; 55: 478-483.

74 Drazen JM, Israel E, O’Byrne PM. Treatment of asthma with drugs modifying the leukotriene pathway. $N$ Engl J Med 1999; 340: 197-206.

75 Lipworth BJ. Leukotriene-receptor antagonists. Lancet 1999; 353: 57-62.

76 Leff JA, Busse WW, Pearlman D, et al. Montelukast, a leukotriene-receptor antagonist, for the treatment of mild asthma and exercise-induced bronchoconstriction. $N$ Engl J Med 1998; 339: 147-152.

77 Noonan MJ, Chervinsky P, Brandon M, et al. Montelukast, a potent leukotriene receptor antagonist, causes dose-related improvements in chronic asthma. Montelukast Asthma Study Group. Eur Respir J 1998; 11: 1232-1239.

78 Reiss TF, Chervinsky P, Dockhorn RJ, Shingo S, Seidenberg B, Edwards TB. Montelukast, a once-daily leukotriene receptor antagonist, in the treatment of chronic asthma: a multicenter, randomized, double-blind trial. Montelukast Clinical Research Study Group. Arch Intern Med 1998; 158: 1213-1220.

79 Dahlen B, Nizankowska E, Szczeklik A, et al. Benefits from adding the 5-lipoxygenase inhibitor zileuton to conventional therapy in aspirin-intolerant asthmatics. Am J Respir Crit Care Med 1998; 157: 1187-1194.

80 Bleecker ER, Welch MJ, Weinstein SF, et al. Low-dose inhaled fluticasone propionate versus oral zafirlukast in the treatment of persistent asthma. J Allergy Clin Immunol 2000; 105: 1123-1129.

81 Laviolette M, Malmstrom K, Lu S, et al. Montelukast added to inhaled beclomethasone in treatment of asthma. Montelukast/Beclomethasone Additivity Group. Am J Respir Crit Care Med 1999; 160: 1862-1868.

82 Lofdahl CG, Reiss TF, Leff JA, et al. Randomised, placebo controlled trial of effect of a leukotriene receptor antagonist, montelukast, on tapering inhaled corticosteroids in asthmatic patients. BMJ 1999; 319: 87-90.

83 Price DB, Hernandez D, Magyar P, et al. Randomised controlled trial of montelukast plus inhaled budesonide versus double dose inhaled budesonide in adult patients with asthma. Thorax 2003; 58: 211-216.

84 Vaquerizo MJ, Casan P, Castillo J, et al. Effect of montelukast added to inhaled budesonide on control of mild to moderate asthma. Thorax 2003; 58: 204-210.

85 Virchow JC, Prasse A, Naya I, Summerton L, Harris A. Zafirlukast improves asthma control in patients receiving high-dose inhaled corticosteroids. Am J Respir Crit Care Med 2000; 162: 578-585.

86 Bjermer L, Bisgaard H, Bousquet J, et al. Montelukast and fluticasone compared with salmeterol and fluticasone in protecting against asthma exacerbation in adults: one year, double blind, randomised, comparative trial. BM] 2003; 327: 891.

87 Deykin A, Wechsler ME, Boushey HA, et al. Combination therapy with a long-acting $\beta$-agonist and a leukotriene antagonist in moderate asthma. Am J Respir Crit Care Med 2007; 175: 228-234.

88 Fish JE, Israel E, Murray JJ, et al. Salmeterol powder provides significantly better benefit than montelukast in asthmatic patients receiving concomitant inhaled corticosteroid therapy. Chest 2001; 120: 423-430.

89 Nelson HS, Busse WW, Kerwin E, et al. Fluticasone propionate/salmeterol combination provides more effective asthma control than low-dose inhaled corticosteroid plus montelukast. J Allergy Clin Immunol 2000; 106: 10881095.

90 Ringdal N, Eliraz A, Pruzinec R, et al. The salmeterol/ fluticasone combination is more effective than fluticasone plus oral montelukast in asthma. Respir Med 2003; 97: 234-241.

91 Harrold LR, Andrade SE, Go AS, et al. Incidence of Churg-Strauss syndrome in asthma drug users: a population-based perspective. I Rheumatol 2005; 32: 1076-1080.

92 Wechsler ME, Finn D, Gunawardena D, et al. ChurgStrauss syndrome in patients receiving montelukast as treatment for asthma. Chest 2000; 117: 708-713.

93 Wechsler ME, Pauwels R, Drazen JM. Leukotriene modifiers and Churg-Strauss syndrome: adverse effect or response to corticosteroid withdrawal? Drug Saf 1999; 21: 241-251.

94 Gibson PG, Powell H, Ducharme FM. Differential effects of maintenance long-acting $\beta$-agonist and inhaled corticosteroid on asthma control and asthma exacerbations. $J$ Allergy Clin Immunol 2007; 119: 344-350.

95 Lazarus SC, Boushey HA, Fahy JV, et al. Long-acting $\beta_{-{ }^{-}}$ agonist monotherapy versus continued therapy with inhaled corticosteroids in patients with persistent asthma: a randomized controlled trial. JAMA 2001; 285: 2583-2593.

96 Lemanske RF Jr, Sorkness CA, Mauger EA, et al. Inhaled corticosteroid reduction and elimination in patients with persistent asthma receiving salmeterol: a randomized controlled trial. JAMA 2001; 285: 2594-2603.

97 Kesten S, Chapman KR, Broder I, et al. A three-month comparison of twice daily inhaled formoterol versus four 
times daily inhaled albuterol in the management of stable asthma. Am Rev Respir Dis 1991; 144: 622-625.

98 Pearlman DS, Chervinsky P, LaForce C, et al. A comparison of salmeterol with albuterol in the treatment of mild-to-moderate asthma. N Engl J Med 1992; 327: 1420-1425.

99 Wenzel SE, Lumry W, Manning M, et al. Efficacy, safety, and effects on quality of life of salmeterol versus albuterol in patients with mild to moderate persistent asthma. Ann Allergy Asthma Immunol 1998; 80: 463-470.

100 Greening AP, Ind PW, Northfield M, Shaw G. Added salmeterol versus higher-dose corticosteroid in asthma patients with symptoms on existing inhaled corticosteroid. Allen \& Hanburys Limited UK Study Group. Lancet 1994; 344: 219-224.

101 Shrewsbury S, Pyke S, Britton M. Meta-analysis of increased dose of inhaled steroid or addition of salmeterol in symptomatic asthma (MIASMA). BMJ 2000; 320: 1368-1373.

102 Woolcock A, Lundback B, Ringdal N, Jacques LA. Comparison of addition of salmeterol to inhaled steroids with doubling of the dose of inhaled steroids. Am J Respir Crit Care Med 1996; 153: 1481-1488.

103 Kips JC, O'Connor BJ, Inman MD, Svensson K, Pauwels RA, O'Byrne PM. A long-term study of the antiinflammatory effect of low-dose budesonide plus formoterol versus high-dose budesonide in asthma. Am J Respir Crit Care Med 2000; 161: 996-1001.

104 Lalloo UG, Malolepszy J, Kozma D, et al. Budesonide and formoterol in a single inhaler improves asthma control compared with increasing the dose of corticosteroid in adults with mild-to-moderate asthma. Chest 2003; 123: 1480-1487.

105 Newnham DM, McDevitt DG, Lipworth BJ. Bronchodilator subsensitivity after chronic dosing with eformoterol in patients with asthma. Am J Med 1994; 97: 29-37.

106 Nelson HS, Weiss ST, Bleecker ER, Yancey SW, Dorinsky PM. The Salmeterol Multicenter Asthma Research Trial: a comparison of usual pharmacotherapy for asthma or usual pharmacotherapy plus salmeterol. Chest 2006; 129: 15-26.

107 US Food and Drug Administration. Advair Diskus, Advair HFA, Brovana, Foradil, Serevent Diskus, and Symbicort Information (Long Acting Beta Agonists) www.fda.gov/cder/drug/infopage/LABA/default.htm Date last updated: October 16, 2006. Date last accessed: November 15, 2006.

108 About Health Canada. Safety information about a class of asthma drugs known as long-acting $\beta_{2}$ agonists www.hcsc.gc.ca/ahc-asc/media/advisories-avis/2005/2005_107_e. html Date last updated: September 12, 2003. Date last accessed: November 15, 2006.

109 Barnes PJ. Theophylline: new perspectives for an old drug. Am J Respir Crit Care Med 2003; 167: 813-818.

110 Kidney J, Dominguez M, Taylor PM, Rose M, Chung KF, Barnes PJ. Immunomodulation by theophylline in asthma. Demonstration by withdrawal of therapy. Am J Respir Crit Care Med 1995; 151: 1907-1914.

111 Sullivan P, Bekir S, Jaffar Z, Page C, Jeffery P, Costello J. Anti-inflammatory effects of low-dose oral theophylline in atopic asthma. Lancet 1994; 343: 1006-1008.
112 Dahl R, Larsen BB, Venge P. Effect of long-term treatment with inhaled budesonide or theophylline on lung function, airway reactivity and asthma symptoms. Respir Med 2002; 96: 432-438.

113 Davies B, Brooks G, Devoy M. The efficacy and safety of salmeterol compared to theophylline: meta-analysis of nine controlled studies. Respir Med 1998; 92: 256-263.

114 Wilson AJ, Gibson PG, Coughlan J. Long acting $\beta$ agonists versus theophylline for maintenance treatment of asthma. Cochrane Database Syst Rev 2000; CD001281.

115 Evans DJ, Taylor DA, Zetterstrom O, Chung KF, O'Connor BJ, Barnes PJ. A comparison of low-dose inhaled budesonide plus theophylline and high-dose inhaled budesonide for moderate asthma. $N$ Engl J Med 1997; 337: 1412-1418.

116 Rivington RN, Boulet LP, Cote J, et al. Efficacy of Uniphyl, salbutamol, and their combination in asthmatic patients on high-dose inhaled steroids. Am J Respir Crit Care Med 1995; 151: 325-332.

117 Ukena D, Harnest U, Sakalauskas R, et al. Comparison of addition of theophylline to inhaled steroid with doubling of the dose of inhaled steroid in asthma. Eur Respir J 1997; 10: 2754-2760.

118 Humbert M, Beasley R, Ayres J, et al. Benefits of omalizumab as add-on therapy in patients with severe persistent asthma who are inadequately controlled despite best available therapy (GINA 2002 step 4 treatment): INNOVATE. Allergy 2005; 60: 309-316.

119 Busse W, Corren J, Lanier BQ, et al. Omalizumab, anti-IgE recombinant humanized monoclonal antibody, for the treatment of severe allergic asthma. J Allergy Clin Immunol 2001; 108: 184-190.

120 Milgrom H, Fick RB Jr, Su JQ, et al. Treatment of allergic asthma with monoclonal anti-IgE antibody. rhuMAb-E25 Study Group. N Engl J Med 1999; 341: 1966-1973.

121 Bousquet J, Wenzel S, Holgate S, Lumry W, Freeman P, Fox H. Predicting response to omalizumab, an anti-IgE antibody, in patients with allergic asthma. Chest 2004; 125: 1378-1386.

122 Djukanovic R, Wilson SJ, Kraft M, et al. Effects of treatment with anti-immunoglobulin $\mathrm{E}$ antibody omalizumab on airway inflammation in allergic asthma. Am J Respir Crit Care Med 2004; 170: 583-593.

123 Holgate ST, Chuchalin AG, Hebert J, et al. Efficacy and safety of a recombinant anti-immunoglobulin E antibody (omalizumab) in severe allergic asthma. Clin Exp Allergy 2004; 34: 632-638.

124 Recommendations for the prevention and treatment of glucocorticoid- induced osteoporosis. American College of Rheumatology Task Force on Osteoporosis Guidelines. Arthritis Rheum 1996; 39: 1791-1801.

125 Campbell IA, Douglas JG, Francis RM, Prescott RJ, Reid DM. Five year study of etidronate and/or calcium as prevention and treatment for osteoporosis and fractures in patients with asthma receiving long term oral and/or inhaled glucocorticoids. Thorax 2004; 59: 761-768.

126 Eastell R, Reid DM, Compston J, et al. A UK Consensus Group on management of glucocorticoid-induced osteoporosis: an update. J Intern Med 1998; 244: 271-292. 
127 Kurosawa M. Anti-allergic drug use in Japan-the rationale and the clinical outcome. Clin Exp Allergy 1994; 24: 299-306.

128 Aaron SD, Dales RE, Pham B. Management of steroiddependent asthma with methotrexate: a meta-analysis of randomized clinical trials. Respir Med 1998; 92: 1059-1065.

129 Marin MG. Low-dose methotrexate spares steroid usage in steroid-dependent asthmatic patients: a meta-analysis. Chest 1997; 112: 29-33.

130 Davies H, Olson L, Gibson P. Methotrexate as a steroid sparing agent for asthma in adults. Cochrane Database Syst Rev 2000; CD000391.

131 Lock SH, Kay AB, Barnes NC. Double-blind, placebocontrolled study of cyclosporin $\mathrm{A}$ as a corticosteroidsparing agent in corticosteroid-dependent asthma. Am J Respir Crit Care Med 1996; 153: 509-514.

132 Bernstein IL, Bernstein DI, Dubb JW, Faiferman I, Wallin B. A placebo-controlled multicenter study of auranofin in the treatment of patients with corticosteroiddependent asthma. Auranofin Multicenter Drug Trial. J Allergy Clin Immunol 1996; 98: 317-324.

133 Nierop G, Gijzel WP, Bel EH, Zwinderman AH, Dijkman JH. Auranofin in the treatment of steroid dependent asthma: a double blind study. Thorax 1992; 47: 349-354.

134 Richeldi L, Ferrara G, Fabbri L, Lasserson T, Gibson P. Macrolides for chronic asthma. Cochrane Database Syst Rev 2005; CD002997.

135 Jakobsson T, Croner S, Kjellman NI, Pettersson A, Vassella C, Bjorksten B. Slight steroid-sparing effect of intravenous immunoglobulin in children and adolescents with moderately severe bronchial asthma. Allergy 1994; 49: 413-420.

136 Kishiyama JL, Valacer D, Cunningham-Rundles C, et al. A multicenter, randomized, double-blind, placebo-controlled trial of high-dose intravenous immunoglobulin for oral corticosteroid-dependent asthma. Clin Immunol 1999; 91: 126-133.

137 Salmun LM, Barlan I, Wolf HM, et al. Effect of intravenous immunoglobulin on steroid consumption in patients with severe asthma: a double-blind, placebocontrolled, randomized trial. J Allergy Clin Immunol 1999; 103: 810-815.

138 Abramson MJ, Puy RM, Weiner JM. Allergen immunotherapy for asthma. Cochrane Database Syst Rev 2003; CD001186.

139 Calamita Z, Saconato H, Pela AB, Atallah AN. Efficacy of sublingual immunotherapy in asthma: systematic review of randomized-clinical trials using the Cochrane Collaboration method. Allergy 2006; 61: 1162-1172.

140 Tamaoki J, Chiyotani A, Tagaya E, Sakai N, Konno K. Effect of long term treatment with oxitropium bromide on airway secretion in chronic bronchitis and diffuse panbronchiolitis. Thorax 1994; 49: 545-548.

141 Bisgaard H. Delivery of inhaled medication to children. $J$ Asthma 1997; 34: 443-467.

142 Dolovich MB, Ahrens RC, Hess DR, et al. Device selection and outcomes of aerosol therapy. Evidence-based guidelines: American College of Chest Physicians/American College of Asthma, Allergy, and Immunology. Chest 2005; 127: 335-371.
143 Pedersen S. Inhalers and nebulizers: which to choose and why. Respir Med 1996; 90: 69-77.

144 Cates CJ, Crilly JA, Rowe BH. Holding chambers (spacers) versus nebulisers for $\beta$-agonist treatment of acute asthma. Cochrane Database Syst Rev 2006; CD000052.

145 Agertoft L, Pedersen S. A randomized, double-blind dose reduction study to compare the minimal effective dose of budesonide Turbuhaler and fluticasone propionate Diskhaler. J Allergy Clin Immunol 1997; 99: 773-780.

146 Shapiro G, Bronsky EA, LaForce CF, et al. Dose-related efficacy of budesonide administered via a dry powder inhaler in the treatment of children with moderate to severe persistent asthma. J Pediatr 1998; 132: 976-982.

147 Adams NP, Bestall JB, Malouf R, Lasserson TJ, Jones PW. Inhaled beclomethasone versus placebo for chronic asthma. Cochrane Database Syst Rev 2005; CD002738.

148 Adams NP, Bestall JC, Jones PW, Lasserson TJ, Griffiths $B$, Cates C. Inhaled fluticasone at different doses for chronic asthma in adults and children. Cochrane Database Syst Rev 2005; CD003534.

149 Pauwels RA, Pedersen S, Busse WW, et al. Early intervention with budesonide in mild persistent asthma: a randomised, double-blind trial. Lancet 2003; 361: 10711076.

150 Pedersen S, O'Byrne P. A comparison of the efficacy and safety of inhaled corticosteroids in asthma. Allergy 1997; 52: 1-34.

151 Powell H, Gibson PG. High dose versus low dose inhaled corticosteroid as initial starting dose for asthma in adults and children. Cochrane Database Syst Rev 2004; CD004109.

152 Nielsen KG, Bisgaard H. The effect of inhaled budesonide on symptoms, lung function, and cold air and methacholine responsiveness in 2- to 5-year-old asthmatic children. Am J Respir Crit Care Med 2000; 162: 15001506.

153 Roorda RJ, Mezei G, Bisgaard H, Maden C. Response of preschool children with asthma symptoms to fluticasone propionate. J Allergy Clin Immunol 2001; 108: 540-546.

154 Guilbert TW, Morgan WJ, Zeiger RS, et al. Long-term inhaled corticosteroids in preschool children at high risk for asthma. N Engl J Med 2006; 354: 1985-1997.

155 Bisgaard H, Hermansen MN, Loland L, Halkjaer LB, Buchvald F. Intermittent inhaled corticosteroids in infants with episodic wheezing. N Engl J Med 2006; 354: 1998-2005.

156 Murray CS, Woodcock A, Langley SJ, Morris J, Custovic A. Secondary prevention of asthma by the use of Inhaled Fluticasone propionate in Wheezy Infants (IFWIN): double-blind, randomised, controlled study. Lancet 2006; 368: 754-762.

157 Agertoft L, Pedersen S. Effect of long-term treatment with inhaled budesonide on adult height in children with asthma. N Engl J Med 2000; 343: 1064-1069.

158 Pedersen S. Do inhaled corticosteroids inhibit growth in children? Am J Respir Crit Care Med 2001; 164: 521-535.

159 Sharek PJ, Bergman DA. Beclomethasone for asthma in children: effects on linear growth. Cochrane Database Syst Rev 2000; CD001282.

160 Agertoft L, Pedersen S. Bone mineral density in children with asthma receiving long-term treatment with inhaled budesonide. Am J Respir Crit Care Med 1998; 157: 178-183. 
161 Hopp RJ, Degan JA, Biven RE, Kinberg K, Gallagher GC. Longitudinal assessment of bone mineral density in children with chronic asthma. Ann Allergy Asthma Immunol 1995; 75: 143-148.

162 Kemp JP, Osur S, Shrewsbury SB, et al. Potential effects of fluticasone propionate on bone mineral density in patients with asthma: a 2-year randomized, double-blind, placebo-controlled trial. Mayo Clin Proc 2004; 79: 458-466.

163 Roux C, Kolta S, Desfougeres JL, Minini P, Bidat E. Longterm safety of fluticasone propionate and nedocromil sodium on bone in children with asthma. Pediatrics 2003; 111: e706-e713.

164 Schlienger RG, Jick SS, Meier CR. Inhaled corticosteroids and the risk of fractures in children and adolescents. Pediatrics 2004; 114: 469-473.

165 van Staa TP, Bishop N, Leufkens HG, Cooper C. Are inhaled corticosteroids associated with an increased risk of fracture in children? Osteoporos Int 2004; 15: 785-791.

166 van Staa TP, Cooper C, Leufkens HG, Bishop N. Children and the risk of fractures caused by oral corticosteroids. $J$ Bone Miner Res 2003; 18: 913-918.

167 Todd G, Dunlop K, McNaboe J, Ryan MF, Carson D, Shields MD. Growth and adrenal suppression in asthmatic children treated with high-dose fluticasone propionate. Lancet 1996; 348: 27-29.

168 Shaw L, al-Dlaigan YH, Smith A. Childhood asthma and dental erosion. ASDC J Dent Child 2000; 67, 102-106: 182.

169 Kargul B, Tanboga I, Ergeneli S, Karakoc F, Dagli E. Inhaler medicament effects on saliva and plaque $\mathrm{pH}$ in asthmatic children. J Clin Pediatr Dent 1998; 22: 137-140.

170 Garcia Garcia ML, Wahn U, Gilles L, Swern A, Tozzi CA, Polos P. Montelukast, compared with fluticasone, for control of asthma among 6- to 14-year-old patients with mild asthma: the MOSAIC study. Pediatrics 2005; 116: 360-369.

171 Kemp JP, Dockhorn RJ, Shapiro GG, et al. Montelukast once daily inhibits exercise-induced bronchoconstriction in 6- to 14-year-old children with asthma. J Pediatr 1998; 133: 424-428.

$172 \mathrm{Ng} \mathrm{D}$, Salvio F, Hicks G. Anti-leukotriene agents compared to inhaled corticosteroids in the management of recurrent and/or chronic asthma in adults and children. Cochrane Database Syst Rev 2004; CD002314.

173 Ostrom NK, Decotiis BA, Lincourt WR, et al. Comparative efficacy and safety of low-dose fluticasone propionate and montelukast in children with persistent asthma. J Pediatr 2005; 147: 213-220.

174 Szefler SJ, Phillips BR, Martinez FD, et al. Characterization of within-subject responses to fluticasone and montelukast in childhood asthma. J Allergy Clin Immunol 2005; 115: 233-242.

175 Vidal C, Fernandez-Ovide E, Pineiro J, Nunez R, Gonzalez-Quintela A. Comparison of montelukast versus budesonide in the treatment of exercise-induced bronchoconstriction. Ann Allergy Asthma Immunol 2001; 86: 655-658.

176 de Benedictis FM, del Giudice MM, Forenza N, Decimo F, de Benedictis D, Capristo A. Lack of tolerance to the protective effect of montelukast in exercise-induced bronchoconstriction in children. Eur Respir J 2006; 28: 291-295.
177 Phipatanakul W, Cronin B, Wood RA, et al. Effect of environmental intervention on mouse allergen levels in homes of inner-city Boston children with asthma. Ann Allergy Asthma Immunol 2004; 92: 420-425.

178 Simons FE, Villa JR, Lee BW, et al. Montelukast added to budesonide in children with persistent asthma: a randomized, double-blind, crossover study. J Pediatr 2001; 138: 694-698.

179 Jat GC, Mathew JL, Singh M. Treatment with 400 microg of inhaled budesonide versus 200 microg of inhaled budesonide and oral montelukast in children with moderate persistent asthma: randomized controlled trial. Ann Allergy Asthma Immunol 2006; 97: 397-401.

180 Bisgaard $\mathrm{H}$, Zielen S, Garcia-Garcia ML, et al. Montelukast reduces asthma exacerbations in 2- to 5year-old children with intermittent asthma. Am J Respir Crit Care Med 2005; 171: 315-322.

181 Knorr B, Franchi LM, Bisgaard H, et al. Montelukast, a leukotriene receptor antagonist, for the treatment of persistent asthma in children aged 2 to 5 years. Pediatrics 2001; 108: E48.

182 Bisgaard $H$. Effect of long-acting $\beta 2$ agonists on exacerbation rates of asthma in children. Pediatr Pulmonol 2003; 36: 391-398.

183 Bierman CW, Pierson WE, Shapiro GG, Furukawa CT. Is a uniform round-the-clock theophylline blood level necessary for optimal asthma therapy in the adolescent patient? Am J Med 1988; 85: 17-20.

184 Katz RM, Rachelefsky GS, Siegel S. The effectiveness of the short- and long-term use of crystallized theophylline in asthmatic children. J Pediatr 1978; 92: 663-667.

185 Pedersen S. Treatment of nocturnal asthma in children with a single dose of sustained-release theophylline taken after supper. Clin Allergy 1985; 15: 79-85.

186 Magnussen H, Reuss G, Jorres R. Methylxanthines inhibit exercise-induced bronchoconstriction at low serum theophylline concentration and in a dose-dependent fashion. J Allergy Clin Immunol 1988; 81: 531-537.

187 Brenner M, Berkowitz R, Marshall N, Strunk RC. Need for theophylline in severe steroid-requiring asthmatics. Clin Allergy 1988; 18: 143-150.

188 Nassif EG, Weinberger M, Thompson R, Huntley W. The value of maintenance theophylline in steroid-dependent asthma. N Engl J Med 1981; 304: 71-75.

189 Ellis EF. Theophylline toxicity. J Allergy Clin Immunol 1985; 76: 297-301.

190 Lonnerholm G, Foucard T, Lindstrom B. Oral terbutaline in chronic childhood asthma; effects related to plasma concentrations. Eur J Respir Dis Suppl 1984; 134: 205-210.

191 Williams SJ, Winner SJ, Clark TJ. Comparison of inhaled and intravenous terbutaline in acute severe asthma. Thorax 1981; 36: 629-632.

192 Dinh Xuan AT, Lebeau C, Roche R, Ferriere A, Chaussain M. Inhaled terbutaline administered via a spacer fully prevents exercise-induced asthma in young asthmatic subjects: a double-blind, randomized, placebocontrolled study. J Int Med Res 1989; 17: 506-513.

193 Fuglsang G, Hertz B, Holm EB. No protection by oral terbutaline against exercise-induced asthma in children: a dose-response study. Eur Respir J 1993; 6: 527-530. 
194 Bengtsson B, Fagerstrom PO. Extrapulmonary effects of terbutaline during prolonged administration. Clin Pharmacol Ther 1982; 31: 726-732.

195 McDonald NJ, Bara AI. Anticholinergic therapy for chronic asthma in children over two years of age. Cochrane Database Syst Rev 2003; CD003535.

196 Bailey WC, Richards JM Jr, Brooks CM, Soong SJ, Windsor RA, Manzella BA. A randomized trial to improve self-management practices of adults with asthma. Arch Intern Med 1990; 150: 1664-1668.

197 Charlton I, Charlton G, Broomfield J, Mullee MA. Evaluation of peak flow and symptoms only self management plans for control of asthma in general practice. BMJ 1990; 301: 1355-1359.

198 Cote J, Cartier A, Robichaud P, et al. Influence on asthma morbidity of asthma education programs based on selfmanagement plans following treatment optimization. Am J Respir Crit Care Med 1997; 155: 1509-1514.

199 Cowie RL, Revitt SG, Underwood MF, Field SK. The effect of a peak flow-based action plan in the prevention of exacerbations of asthma. Chest 1997; 112: 1534-1538.

200 Ignacio-Garcia JM, Gonzalez-Santos P. Asthma selfmanagement education program by home monitoring of peak expiratory flow. Am J Respir Crit Care Med 1995; 151: 353-359.

201 Jones KP, Mullee MA, Middleton M, Chapman E, Holgate ST. Peak flow based asthma self-management: a randomised controlled study in general practice. British Thoracic Society Research Committee. Thorax 1995; 50: 851-857.

202 Kohler CL, Davies SL, Bailey WC. How to implement an asthma education program. Clin Chest Med 1995; 16: 557-565.

203 Lahdensuo A, Haahtela T, Herrala J, et al. Randomised comparison of guided self management and traditional treatment of asthma over one year. BMJ 1996; 312: 748-752.

204 Sommaruga M, Spanevello A, Migliori GB, Neri M, Callegari S, Majani G. The effects of a cognitive behavioural intervention in asthmatic patients. Monaldi Arch Chest Dis 1995; 50: 398-402.

205 Turner MO, Taylor D, Bennett R, FitzGerald JM. A randomized trial comparing peak expiratory flow and symptom self-management plans for patients with asthma attending a primary care clinic. Am J Respir Crit Care Med 1998; 157: 540-546.

206 Chan DS, Callahan CW, Hatch-Pigott VB, et al. Internetbased home monitoring and education of children with asthma is comparable to ideal office-based care: results of a 1-year asthma in-home monitoring trial. Pediatrics 2007; 119: 569-578.

207 Murphy VE, Gibson PG, Talbot PI, Kessell CG, Clifton VL. Asthma self-management skills and the use of asthma education during pregnancy. Eur Respir J 2005; 26: 435-441.

208 Guevara JP, Wolf FM, Grum CM, Clark NM. Effects of educational interventions for self management of asthma in children and adolescents: systematic review and metaanalysis. BMJ 2003; 326: 1308-1309.

209 Shah S, Peat JK, Mazurski EJ, et al. Effect of peer led programme for asthma education in adolescents: cluster randomised controlled trial. BMJ 2001; 322: 583-585.
210 Griffiths C, Foster G, Barnes N, et al. Specialist nurse intervention to reduce unscheduled asthma care in a deprived multiethnic area: the east London randomised controlled trial for high risk asthma (ELECTRA). BMJ 2004; 328: 144.

211 Gibson PG, Powell H, Coughlan J, et al. Self-management education and regular practitioner review for adults with asthma. Cochrane Database Syst Rev 2003; CD001117.

212 Gibson PG, Powell H, Coughlan J, et al. Limited (information only) patient education programs for adults with asthma. Cochrane Database Syst Rev 2002; CD001005.

213 Haby MM, Waters E, Robertson CF, Gibson PG, Ducharme FM. Interventions for educating children who have attended the emergency room for asthma. Cochrane Database Syst Rev 2001; CD001290.

214 Powell H, Gibson PG. Options for self-management education for adults with asthma. Cochrane Database Syst Rev 2003; CD004107.

215 Cabana MD, Slish KK, Evans D, et al. Impact care education on patient outcomes. Pediatrics 2006; 117: 2149_ 2157.

216 Levy M, Bell L. General practice audit of asthma in childhood. BMJ (Clin Res Ed) 1984; 289: 1115-1116.

217 Ong LM, de Haes JC, Hoos AM, Lammes FB. Doctorpatient communication: a review of the literature. Soc Sci Med 1995; 40: 903-918.

218 Stewart MA. Effective physician-patient communication and health outcomes: a review. CMAJ 1995; 152: 14231433.

219 Clark NM, Gong M, Schork MA, et al. Long-term effects of asthma education for physicians on patient satisfaction and use of health services. Eur Respir J 2000; 16: 15-21.

220 Cegala DJ, Marinelli T, Post D. The effects of patient communication skills training on compliance. Arch Fam Med 2000; 9: 57-64.

221 Houts PS, Bachrach R, Witmer JT, Tringali CA, Bucher JA, Localio RA. Using pictographs to enhance recall of spoken medical instructions. Patient Educ Couns 1998; 35: 83-88.

222 Meade CD, McKinney WP, Barnas GP. Educating patients with limited literacy skills: the effectiveness of printed and videotaped materials about colon cancer. Am J Public Health 1994; 84: 119-121.

223 Chapman KR, Voshaar TH, Virchow JC. Inhaler choice in primary care. Eur Respir Rev 2005; 14: 117-122.

224 Voshaar T, App EM, Berdel D, et al. [Recommendations for the choice of inhalatory systems for drug prescription]. Pneumologie 2001; 55: 579-586.

225 Fishwick D, D'Souza W, Beasley R. The asthma selfmanagement plan system of care: what does it mean, how is it done, does it work, what models are available, what do patients want and who needs it? Patient Educ Couns 1997; 32: Suppl. 1, S21-S33.

226 Gibson PG, Powell H. Written action plans for asthma: an evidence-based review of the key components. Thorax 2004; 59: 94-99.

227 Partridge MR, Hill SR. Enhancing care for people with asthma: the role of communication, education, training and self-management. 1998 World Asthma Meeting Education and Delivery of Care Working Group. Eur Respir J 2000; 16: 333-348. 
228 Asthma UK. www.asthma.org.uk Date last updated: November 2, 2007. Date last accessed: November 15, 2006.

229 National Heart, Lung, and Blood Institute. Asthma Management Model System. www.nhlbisupport.com/ asthma/index.html Date last updated: July, 2007. Date last accessed: July 15, 2007.

230 Asthma and Respiratory Foundation, New Zealand. www.asthmanz.co.nz Date last updated: 2007. Date last accessed: July 15, 2007.

231 Newman SP. Inhaler treatment options in COPD. Eur Respir Rev 2005; 14: 102-108.

232 Coutts JA, Gibson NA, Paton JY. Measuring compliance with inhaled medication in asthma. Arch Dis Child 1992; 67: 332-333.

233 Arshad SH. Primary prevention of asthma and allergy. J Allergy Clin Immunol 2005; 116: 3-14.

234 Bousquet J, Yssel H, Vignola AM. Is allergic asthma associated with delayed fetal maturation or the persistence of conserved fetal genes? Allergy 2000; 55: 1194-1197.

235 Jones CA, Holloway JA, Warner JO. Does atopic disease start in foetal life? Allergy 2000; 55: 2-10.

236 Friedman NJ, Zeiger RS. The role of breast-feeding in the development of allergies and asthma. J Allergy Clin Immunol 2005; 115: 1238-1248.

237 Gdalevich M, Mimouni D, Mimouni M. Breast-feeding and the risk of bronchial asthma in childhood: a systematic review with meta-analysis of prospective studies. J Pediatr 2001; 139: 261-266.

238 Robinson DS, Larche M, Durham SR. Tregs and allergic disease. J Clin Invest 2004; 114: 1389-1397.

239 Martinez FD, Wright AL, Taussig LM, Holberg CJ, Halonen M, Morgan WJ. Asthma and wheezing in the first six years of life. The Group Health Medical Associates. N Engl J Med 1995; 332: 133-138.

240 Dezateux C, Stocks J, Dundas I, Fletcher ME. Impaired airway function and wheezing in infancy: the influence of maternal smoking and a genetic predisposition to asthma. Am J Respir Crit Care Med 1999; 159: 403-410.

241 Gotzsche PC, Johansen HK, Schmidt LM, Burr ML. House dust mite control measures for asthma. Cochrane Database Syst Rev 2004; CD001187.

242 Platts-Mills TA. Allergen avoidance in the treatment of asthma and rhinitis. N Engl J Med 2003; 349: 207-208.

243 Sheffer AL. Allergen avoidance to reduce asthma-related morbidity. N Engl J Med 2004; 351: 1134-1136.

244 Chaudhuri R, Livingston E, McMahon AD, et al. Effects of smoking cessation on lung function and airway inflammation in smokers with asthma. Am J Respir Crit Care Med 2006; 174: 127-133.

245 Upham JW, Holt PG. Environment and development of atopy. Curr Opin Allergy Clin Immunol 2005; 5: 167-172.

246 Anto JM, Soriano JB, Sunyer J, et al. Long term outcome of soybean epidemic asthma after an allergen reduction intervention. Thorax 1999; 54: 670-674.

247 Chen LL, Tager IB, Peden DB, et al. Effect of ozone exposure on airway responses to inhaled allergen in asthmatic subjects. Chest 2004; 125: 2328-2335.

248 Marks GB, Colquhoun JR, Girgis ST, et al. Thunderstorm outflows preceding epidemics of asthma during spring and summer. Thorax 2001; 56: 468-471.
249 Newson R, Strachan D, Archibald E, Emberlin J, Hardaker P, Collier C. Acute asthma epidemics, weather and pollen in England, 1987-1994. Eur Respir J 1998; 11: 694-701.

250 Sicherer SH, Sampson HA. 9. Food allergy. J Allergy Clin Immunol 2006; 117: Suppl. 2, S470-S475.

251 Roberts G, Patel N, Levi-Schaffer F, Habibi P, Lack G. Food allergy as a risk factor for life-threatening asthma in childhood: a case-controlled study. J Allergy Clin Immunol 2003; 112: 168-174.

252 Szczeklik A, Nizankowska E, Bochenek G, Nagraba K, Mejza F, Swierczynska M. Safety of a specific COX-2 inhibitor in aspirin-induced asthma. Clin Exp Allergy 2001; 31: 219-225.

253 Covar RA, Macomber BA, Szefler SJ. Medications as asthma triggers. Immunol Allergy Clin North Am 2005; 25: 169-190.

254 Nicholson KG, Nguyen-Van-Tam JS, Ahmed AH, et al. Randomised placebo-controlled crossover trial on effect of inactivated influenza vaccine on pulmonary function in asthma. Lancet 1998; 351: 326-331.

255 Bueving HJ, Bernsen RM, de Jongste JC, et al. Influenza vaccination in children with asthma: randomized doubleblind placebo-controlled trial. Am J Respir Crit Care Med 2004; 169: 488-493.

256 Cates CJ, Jefferson TO, Bara AI, Rowe BH. Vaccines for preventing influenza in people with asthma. Cochrane Database Syst Rev 2004; CD000364.

257 Tantisira KG, Litonjua AA, Weiss ST, Fuhlbrigge AL. Association of body mass with pulmonary function in the Childhood Asthma Management Program (CAMP). Thorax 2003; 58: 1036-1041.

258 Stenius-Aarniala B, Poussa T, Kvarnstrom J, Gronlund EL, Ylikahri M, Mustajoki P. Immediate and long term effects of weight reduction in obese people with asthma: randomised controlled study. BMJ 2000; 320: 827-832.

259 Rietveld S, van Beest I, Everaerd W. Stress-induced breathlessness in asthma. Psychol Med 1999; 29: 1359_ 1366.

260 Sandberg S, Paton JY, Ahola S, et al. The role of acute and chronic stress in asthma attacks in children. Lancet 2000; 356: 982-987.

261 Lehrer PM, Isenberg S, Hochron SM. Asthma and emotion: a review. J Asthma 1993; 30: 5-21.

262 Nouwen A, Freeston MH, Labbe R, Boulet LP. Psychological factors associated with emergency room visits among asthmatic patients. Behav Modif 1999; 23: 217-233.

263 Rachelefsky GS, Katz RM, Siegel SC. Chronic sinus disease with associated reactive airway disease in children. Pediatrics 1984; 73: 526-529.

264 Harding SM, Guzzo MR, Richter JE. The prevalence of gastroesophageal reflux in asthma patients without reflux symptoms. Am J Respir Crit Care Med 2000; 162: 34-39.

265 Patterson PE, Harding SM. Gastroesophageal reflux disorders and asthma. Curr Opin Pulm Med 1999; 5: 63-67.

266 Chien S, Mintz S. Pregnancy and menses. In: Weiss EB, Stein M, eds. Bronchial Asthma Mechanisms and Therapeutics. Boston, Little Brown, 1993; pp. 1085-1098. 
267 Barron WM, Leff AR. Asthma in pregnancy. Am Rev Respir Dis 1993; 147: 510-511.

268 Juniper EF, Bousquet J, Abetz L, Bateman ED. Identifying "well-controlled" and "not well-controlled" asthma using the Asthma Control Questionnaire. Respir Med 2006; 100: 616-621.

269 Juniper EF, Svensson K, Mork AC, Stahl E. Measurement properties and interpretation of three shortened versions of the asthma control questionnaire. Respir Med 2005; 99: 553-558.

270 Bateman ED, Bousquet J, Keech ML, Busse WW, Clark TJ, Pedersen SE. The correlation between asthma control and health status: the GOAL study. Eur Respir J 2007; 29: 5662.

271 O'Byrne PM, Barnes PJ, Rodriguez-Roisin R, et al. Low dose inhaled budesonide and formoterol in mild persistent asthma: the OPTIMA randomized trial. Am J Respir Crit Care Med 2001; 164: 1392-1397.

272 Zeiger RS, Baker JW, Kaplan MS, et al. Variability of symptoms in mild persistent asthma: baseline data from the MIAMI study. Respir Med 2004; 98: 898-905.

273 Using $\beta_{2}$-stimulants in asthma. Drug Ther Bull 1997; 35: 1-4.

274 Godfrey S, Bar-Yishay E. Exercised-induced asthma revisited. Respir Med 1993; 87: 331-344.

275 Pearlman DS, van Adelsberg J, Philip G, et al. Onset and duration of protection against exercise-induced bronchoconstriction by a single oral dose of montelukast. Ann Allergy Asthma Immunol 2006; 97: 98-104.

276 Spooner CH, Saunders LD, Rowe BH. Nedocromil sodium for preventing exercise-induced bronchoconstriction. Cochrane Database Syst Rev 2000; CD001183.

277 Ram FS, Robinson SM, Black PN. Physical training for asthma. Cochrane Database Syst Rev 2000; CD001116.

278 Reiff DB, Choudry NB, Pride NB, Ind PW. The effect of prolonged submaximal warm-up exercise on exerciseinduced asthma. Am Rev Respir Dis 1989; 139: 479-484.

279 Philip G, Nayak AS, Berger WE, et al. The effect of montelukast on rhinitis symptoms in patients with asthma and seasonal allergic rhinitis. Curr Med Res Opin 2004; 20: 1549-1558.

280 Wilson AM, Dempsey OJ, Sims EJ, Lipworth BJ. A comparison of topical budesonide and oral montelukast in seasonal allergic rhinitis and asthma. Clin Exp Allergy 2001; 31: 616-624.

281 Francis RS, McEnery G. Disodium cromoglycate compared with beclomethasone dipropionate in juvenile asthma. Clin Allergy 1984; 14: 537-540.

282 Ostergaard P, Pedersen S. The effect of inhaled disodium cromoglycate and budesonide on bronchial responsiveness to histamine and exercise in asthmatic children: a clinical comparison. In: Godfrey S, ed. Glucocorticosteroids in Childhood Asthma. New York, Elsevier Science Publishing Co., 1987; pp. 55-65.

283 Tasche MJ, Uijen JH, Bernsen RM, de Jongste JC, van der Wouden JC. Inhaled disodium cromoglycate (DSCG) as maintenance therapy in children with asthma: a systematic review. Thorax 2000; 55: 913-920.

284 Tasche MJ, van der Wouden JC, Uijen $\mathrm{JH}$, et al. Randomised placebo-controlled trial of inhaled sodium cromoglycate in 1-4-year-old children with moderate asthma. Lancet 1997; 350: 1060-1064.
285 Boonsawat W, Charoenratanakul S, Pothirat C, et al. Formoterol (OXIS) Turbuhaler as a rescue therapy compared with salbutamol pMDI plus spacer in patients with acute severe asthma. Respir Med 2003; 97: 1067-1074.

286 Ind PW, Villasante C, Shiner RJ, et al. Safety of formoterol by Turbuhaler as reliever medication compared with terbutaline in moderate asthma. Eur Respir J 2002; 20: 859-866.

287 Pauwels RA, Sears MR, Campbell M, et al. Formoterol as relief medication in asthma: a worldwide safety and effectiveness trial. Eur Respir J 2003; 22: 787-794.

288 Tattersfield AE, Town GI, Johnell $\mathrm{O}$, et al. Bone mineral density in subjects with mild asthma randomised to treatment with inhaled corticosteroids or non-corticosteroid treatment for two years. Thorax 2001; 56: 272-278.

289 Balanag VM, Yunus F, Yang PC, Jorup C. Efficacy and safety of budesonide/formoterol compared with salbutamol in the treatment of acute asthma. Pulm Pharmacol Ther 2006; 19: 139-147.

290 Bateman ED, Fairall L, Lombardi DM, English R. Budesonide/formoterol and formoterol provide similar rapid relief in patients with acute asthma showing refractoriness to salbutamol. Respir Res 2006; 7: 13.

291 Bisgaard $H$. Long-acting $\beta_{2}$-agonists in management of childhood asthma: A critical review of the literature. Pediatr Pulmonol 2000; 29: 221-234.

292 Verberne AA, Frost C, Duiverman EJ, Grol MH, Kerrebijn KF. Addition of salmeterol versus doubling the dose of beclomethasone in children with asthma. The Dutch Asthma Study Group. Am J Respir Crit Care Med 1998; 158: 213-219.

293 O'Byrne PM, Bisgaard H, Godard PP, et al. Budesonide/ formoterol combination therapy as both maintenance and reliever medication in asthma. Am J Respir Crit Care Med 2005; 171: 129-136.

294 Rabe KF, Pizzichini E, Stallberg B, et al. Budesonide/ formoterol in a single inhaler for maintenance and relief in mild-to-moderate asthma: a randomized, double-blind trial. Chest 2006; 129: 246-256.

295 Scicchitano R, Aalbers R, Ukena D, et al. Efficacy and safety of budesonide/formoterol single inhaler therapy versus a higher dose of budesonide in moderate to severe asthma. Curr Med Res Opin 2004; 20: 1403-1418.

296 Vogelmeier C, D’Urzo A, Pauwels R, et al. Budesonide/ formoterol maintenance and reliever therapy: an effective asthma treatment option? Eur Respir J 2005; 26: 819-828.

297 Cates CC, Bara A, Crilly JA, Rowe BH. Holding chambers versus nebulisers for $\beta$-agonist treatment of acute asthma. Cochrane Database Syst Rev 2003; CD000052.

298 Turner MO, Patel A, Ginsburg S, FitzGerald JM. Bronchodilator delivery in acute airflow obstruction. A meta-analysis. Arch Intern Med 1997; 157: 1736-1744.

299 Pedersen S, Hansen OR. Budesonide treatment of moderate and severe asthma in children: a dose-response study. J Allergy Clin Immunol 1995; 95: 29-33.

300 Clinical trial of low-dose theophylline and montelukast in patients with poorly controlled asthma. Am J Respir Crit Care Med 2007; 175: 235-242.

301 Malone R, LaForce C, Nimmagadda S, et al. The safety of twice-daily treatment with fluticasone propionate and 
salmeterol in pediatric patients with persistent asthma. Ann Allergy Asthma Immunol 2005; 95: 66-71.

302 Toogood JH, Baskerville JC, Jennings B, Lefcoe NM, Johansson SA. Influence of dosing frequency and schedule on the response of chronic asthmatics to the aerosol steroid, budesonide. J Allergy Clin Immunol 1982; 70: 288-298.

303 Tamaoki J, Kondo M, Sakai N, et al. Leukotriene antagonist prevents exacerbation of asthma during reduction of high-dose inhaled corticosteroid. The Tokyo Joshi-Idai Asthma Research Group. Am J Respir Crit Care Med 1997; 155: 1235-1240.

304 Mash B, Bheekie A, Jones PW. Inhaled versus oral steroids for adults with chronic asthma. Cochrane Database Syst Rev 2000; CD002160.

305 Ayres JG, Jyothish D, Ninan T. Brittle asthma. Paediatr Respir Rev 2004; 5: 40-44.

306 Reddel HK, Jenkins CR, Marks GB, et al. Optimal asthma control, starting with high doses of inhaled budesonide. Eur Respir J 2000; 16: 226-235.

307 Sont JK, Willems LN, Bel EH, van Krieken JH, Vandenbroucke JP, Sterk PJ. Clinical control and histopathologic outcome of asthma when using airway hyperresponsiveness as an additional guide to long-term treatment. The AMPUL Study Group. Am J Respir Crit Care Med 1999; 159: 1043-1051.

308 Hawkins G, McMahon AD, Twaddle S, Wood SF, Ford I, Thomson NC. Stepping down inhaled corticosteroids in asthma: randomised controlled trial. BMJ 2003; 326: 1115.

309 Powell H, Gibson PG. Initial starting dose of inhaled corticosteroids in adults with asthma: a systematic review. Thorax 2004; 59: 1041-1045.

310 Boulet LP, Drollmann A, Magyar P, et al. Comparative efficacy of once-daily ciclesonide and budesonide in the treatment of persistent asthma. Respir Med 2006; 100: 785-794.

311 Masoli M, Weatherall M, Holt S, Beasley R. Budesonide once versus twice-daily administration: meta-analysis. Respirology 2004; 9: 528-534.

312 FitzGerald JM, Boulet LP, Follows RM. CONCEPT: A one year, multi centre, randomized double blind, doubledummy comparison of salmeterol/fluticasone propionate using a stable dosing regimen with formoterol/ budesonide using an adjustable maintenance regimen in adults with persistent asthma. Clin Ther 2005; 27: 393-406.

313 Reddel HK, Barnes DJ. Pharmacological strategies for self-management of asthma exacerbations. Eur Respir J 2006; 28: 182-199.

314 Harrison TW, Oborne J, Newton S, Tattersfield AE. Doubling the dose of inhaled corticosteroid to prevent asthma exacerbations: randomised controlled trial. Lancet 2004; 363: 271-275.

315 Rabe KF, Atienza T, Magyar P, Larsson P, Jorup C, Lalloo UG. Effect of budesonide in combination with formoterol for reliever therapy in asthma exacerbations: a randomised controlled, double-blind study. Lancet 2006; 368: 744-753.

316 Bisgaard H, Le Roux P, Bjamer D, Dymek A, Vermeulen JH, Hultquist C. Budesonide/formoterol maintenance plus reliever therapy: a new strategy in pediatric asthma. Chest 2006; 130: 1733-1743.
317 Wenzel S. Severe asthma in adults. Am J Respir Crit Care Med 2005; 172: 149-160.

318 Heaney LG, Robinson DS. Severe asthma treatment: need for characterising patients. Lancet 2005; 365: 974-976.

319 FitzGerald JM, Grunfeld A. Status asthmaticus. In: Lichtenstein LM, Fauci AS, eds. Current Therapy in Allergy, Immunology, and Rheumatology. 5th Edn. St Louis, Mosby, 1996; pp. 63-67.

320 Chan-Yeung M, Chang JH, Manfreda J, Ferguson A, Becker A. Changes in peak flow, symptom score, and the use of medications during acute exacerbations of asthma. Am J Respir Crit Care Med 1996; 154: 889-893.

321 Beasley R, Miles J, Fishwick D, Leslie H. Management of asthma in the hospital emergency department. Br J Hosp Med 1996; 55: 253-257.

322 FitzGerald JM. Development and implementation of asthma guidelines. Can Respir J 1998; 5: Suppl. A, 85S-88S.

323 Turner MO, Noertjojo K, Vedal S, Bai T, Crump S, FitzGerald JM. Risk factors for near-fatal asthma. A casecontrol study in hospitalized patients with asthma. Am J Respir Crit Care Med 1998; 157: 1804-1809.

324 Ernst $\mathrm{P}$, Spitzer WO, Suissa S, et al. Risk of fatal and nearfatal asthma in relation to inhaled corticosteroid use. JAMA 1992; 268: 3462-3464.

325 Suissa S, Blais L, Ernst P. Patterns of increasing $\beta$-agonist use and the risk of fatal or near-fatal asthma. Eur Respir $J$ 1994; 7: 1602-1609.

326 Serrano J, Plaza V, Sureda B, et al. Alexithymia: a relevant psychological variable in near-fatal asthma. Eur Respir J 2006; 28: 296-302.

327 Joseph KS, Blais L, Ernst P, Suissa S. Increased morbidity and mortality related to asthma among asthmatic patients who use major tranquillisers. BMJ 1996; 312: 79-82.

328 Geelhoed GC, Landau LI, Le Souef PN. Evaluation of $\mathrm{SaO}_{2}$ as a predictor of outcome in 280 children presenting with acute asthma. Ann Emerg Med 1994; 23: 1236-1241.

329 Plotnick LH, Ducharme FM. Should inhaled anticholinergics be added to $\beta 2$ agonists for treating acute childhood and adolescent asthma? A systematic review. BMJ 1998; 317: 971-977.

330 Atta JA, Nunes MP, Fonseca-Guedes $\mathrm{CH}$, et al. Patient and physician evaluation of the severity of acute asthma exacerbations. Braz J Med Biol Res 2004; 37: 1321-1330.

331 Shim CS, Williams MH Jr. Evaluation of the severity of asthma: patients versus physicians. Am J Med 1980; 68: 11-13.

332 Nowak RM, Tomlanovich MC, Sarkar DD, Kvale PA, Anderson JA. Arterial blood gases and pulmonary function testing in acute bronchial asthma. Predicting patient outcomes. JAMA 1983; 249: 2043-2046.

333 Findley LJ, Sahn SA. The value of chest roentgenograms in acute asthma in adults. Chest 1981; 80: 535-536.

334 Cates C, FitzGerald JM, O'Byrne PM. Asthma. Clin Evidence 2000; 3: 686-700.

335 Chien JW, Ciufo R, Novak R, et al. Uncontrolled oxygen administration and respiratory failure in acute asthma. Chest 2000; 117: 728-733.

336 Rodrigo GJ, Rodriquez Verde M, Peregalli V, Rodrigo C. Effects of short-term $28 \%$ and $100 \%$ oxygen on $\mathrm{PaCO}_{2}$ and 
peak expiratory flow rate in acute asthma: a randomized trial. Chest 2003; 124: 1312-1317.

337 Lin RY, Sauter D, Newman T, Sirleaf J, Walters J, Tavakol M. Continuous versus intermittent albuterol nebulization in the treatment of acute asthma. Ann Emerg Med 1993; 22: 1847-1853.

338 Reisner C, Kotch A, Dworkin G. Continuous versus frequent intermittent nebulization of albuterol in acute asthma: a randomized, prospective study. Ann Allergy Asthma Immunol 1995; 75: 41-47.

339 Rudnitsky GS, Eberlein RS, Schoffstall JM, Mazur JE, Spivey WH. Comparison of intermittent and continuously nebulized albuterol for treatment of asthma in an urban emergency department. Ann Emerg Med 1993; 22: 1842-1846.

340 Bradding P, Rushby I, Scullion J, Morgan MD. Asrequired versus regular nebulized salbutamol for the treatment of acute severe asthma. Eur Respir J 1999; 13: 290-294.

341 Rodrigo GJ, Rodrigo C. Continuous versus intermittent $\beta$ agonists in the treatment of acute adult asthma: a systematic review with meta-analysis. Chest 2002; 122: 160-165.

342 Travers A, Jones AP, Kelly K, Barker SJ, Camargo CA, Rowe $\mathrm{BH}$. Intravenous $\beta_{2}$-agonists for acute asthma in the emergency department. Cochrane Database Syst Rev 2001; CD002988.

343 Rodrigo G, Rodrigo C, Burschtin O. A meta-analysis of the effects of ipratropium bromide in adults with acute asthma. Am J Med 1999; 107: 363-370.

344 Lanes SF, Garrett JE, Wentworth CE 3rd, Fitzgerald JM, Karpel JP. The effect of adding ipratropium bromide to salbutamol in the treatment of acute asthma: a pooled analysis of three trials. Chest 1998; 114: 365-372.

345 Rodrigo GJ, Rodrigo C. First-line therapy for adult patients with acute asthma receiving a multiple-dose protocol of ipratropium bromide plus albuterol in the emergency department. Am J Respir Crit Care Med 2000; 161: 1862-1868.

346 Goggin N, Macarthur C, Parkin PC. Randomized trial of the addition of ipratropium bromide to albuterol and corticosteroid therapy in children hospitalized because of an acute asthma exacerbation. Arch Pediatr Adolesc Med 2001; 155: 1329-1334.

347 Parameswaran K, Belda J, Rowe BH. Addition of intravenous aminophylline to $\beta_{2}$-agonists in adults with acute asthma. Cochrane Database Syst Rev 2000; CD002742.

348 Ream RS, Loftis LL, Albers GM, Becker BA, Lynch RE, Mink RB. Efficacy of IV theophylline in children with severe status asthmaticus. Chest 2001; 119: 1480-1488.

349 Manser R, Reid D, Abramson M. Corticosteroids for acute severe asthma in hospitalised patients. Cochrane Database Syst Rev 2000; CD001740.

350 Rowe BH, Bota GW, Fabris L, Therrien SA, Milner RA, Jacono J. Inhaled budesonide in addition to oral corticosteroids to prevent asthma relapse following discharge from the emergency department: a randomized controlled trial. JAMA 1999; 281: 2119-2126.

351 Harrison BD, Stokes TC, Hart GJ, Vaughan DA, Ali NJ, Robinson AA. Need for intravenous hydrocortisone in addition to oral prednisolone in patients admitted to hospital with severe asthma without ventilatory failure. Lancet 1986; 1: 181-184.

352 Ratto D, Alfaro C, Sipsey J, Glovsky MM, Sharma OP. Are intravenous corticosteroids required in status asthmaticus? JAMA 1988; 260: 527-529.

353 Gries DM, Moffitt DR, Pulos E, Carter ER. A single dose of intramuscularly administered dexamethasone acetate is as effective as oral prednisone to treat asthma exacerbations in young children. J Pediatr 2000; 136: 298-303.

354 Rowe BH, Spooner C, Ducharme FM, Bretzlaff JA, Bota GW. Early emergency department treatment of acute asthma with systemic corticosteroids. Cochrane Database Syst Rev 2000; CD002178.

355 Kayani S, Shannon DC. Adverse behavioral effects of treatment for acute exacerbation of asthma in children: a comparison of two doses of oral steroids. Chest 2002; 122: 624-628.

356 Hasegawa T, Ishihara K, Takakura S, et al. Duration of systemic corticosteroids in the treatment of asthma exacerbation; a randomized study. Intern Med 2000; 39: 794-797.

357 O'Driscoll BR, Kalra S, Wilson M, Pickering CA, Carroll KB, Woodcock AA. Double-blind trial of steroid tapering in acute asthma. Lancet 1993; 341: 324-327.

358 Lederle FA, Pluhar RE, Joseph AM, Niewoehner DE. Tapering of corticosteroid therapy following exacerbation of asthma. A randomized, double-blind, placebo-controlled trial. Arch Intern Med 1987; 147: 2201-2203.

359 Rodrigo G, Rodrigo C. Inhaled flunisolide for acute severe asthma. Am J Respir Crit Care Med 1998; 157: 698-703.

360 Rodrigo GJ. Comparison of inhaled fluticasone with intravenous hydrocortisone in the treatment of adult acute asthma. Am J Respir Crit Care Med 2005; 171: 12311236.

361 Lee-Wong M, Dayrit FM, Kohli AR, Acquah S, Mayo PH. Comparison of high-dose inhaled flunisolide to systemic corticosteroids in severe adult asthma. Chest 2002; 122: 1208-1213.

362 Nana A, Youngchaiyud P, Charoenratanakul S, et al. High-dose inhaled budesonide may substitute for oral therapy after an acute asthma attack. J Asthma 1998; 35: 647-655.

363 FitzGerald JM, Shragge D, Haddon J, et al. A randomized controlled trial of high dose, inhaled budesonide versus oral prednisone in patients discharged from the emergency department following an acute asthma exacerbation. Can Respir J 2000; 7: 61-67.

364 Edmonds ML, Camargo CA, Saunders LD, Brenner BE, Rowe $\mathrm{BH}$. Inhaled steroids in acute asthma following emergency department discharge (Cochrane review). Cochrane Database Syst Rev 2000; CD002316.

365 FitzGerald JM. Magnesium sulfate is effective for severe acute asthma treated in the emergency department. West J Med 2000; 172: 96.

366 Rowe BH, Bretzlaff JA, Bourdon C, Bota GW, Camargo CA Jr. Magnesium sulfate for treating exacerbations of acute asthma in the emergency department. Cochrane Database Syst Rev 2000; CD001490. 
367 Blitz M, Blitz S, Beasely $\mathrm{R}$, et al. Inhaled magnesium sulfate in the treatment of acute asthma. Cochrane Database Syst Rev, 2005: CD003898.

368 Blitz M, Blitz S, Hughes R, et al. Aerosolized magnesium sulfate for acute asthma: a systematic review. Chest 2005; 128: 337-344.

369 Colebourn CL, Barber V, Young JD. Use of heliumoxygen mixture in adult patients presenting with exacerbations of asthma and chronic obstructive pulmonary disease: a systematic review. Anaesthesia 2007; 62: 34-42.

370 FitzGerald JM, Macklem P. Fatal asthma. Annu Rev Med 1996; 47: 161-168.

371 Grunfeld A, Fitzgerald JM. Discharge considerations in acute asthma. Can Respir J 1996; 3: 322-324.

372 Rodrigo GJ, Rodrigo C, Hall JB. Acute asthma in adults: a review. Chest 2004; 125: 1081-1102.

373 Zeiger RS, Heller S, Mellon MH, Wald J, Falkoff R, Schatz M. Facilitated referral to asthma specialist reduces relapses in asthma emergency room visits. J Allergy Clin Immunol 1991; 87: 1160-1168.

374 Gibson PG, Coughlan J, Wilson AJ, et al. Self-management education and regular practitioner review for adults with asthma. Cochrane Database Syst Rev 2000; CD001117.

375 Demissie K, Breckenridge MB, Rhoads GG. Infant and maternal outcomes in the pregnancies of asthmatic women. Am J Respir Crit Care Med 1998; 158: 1091-1095.

376 Schatz M. Interrelationships between asthma and pregnancy: a literature review. J Allergy Clin Immunol 1999; 103: S330-S336.

377 Schatz M, Zeiger RS, Hoffman CP, et al. Perinatal outcomes in the pregnancies of asthmatic women: a prospective controlled analysis. Am J Respir Crit Care Med 1995; 151: 1170-1174.

378 Murphy VE, Gibson PG, Smith R, Clifton VL. Asthma during pregnancy: mechanisms and treatment implications. Eur Respir J 2005; 25: 731-750.

379 NAEPP expert panel report. Managing asthma during pregnancy: recommendations for pharmacologic treatment - 2004 update. J Allergy Clin Immunol 2005; 115: 34-46.

380 Schatz M, Harden K, Forsythe A, et al. The course of asthma during pregnancy, post partum, and with successive pregnancies: a prospective analysis. J Allergy Clin Immunol 1988; 81: 509-517.

381 Schatz M, Zeiger RS, Harden KM, et al. The safety of inhaled beta-agonist bronchodilators during pregnancy. $J$ Allergy Clin Immunol 1988; 82: 686-695.

382 Fung DL. Emergency anesthesia for asthma patients. Clin Rev Allergy 1985; 3: 127-141.

383 Kingston HG, Hirshman CA. Perioperative management of the patient with asthma. Anesth Analg 1984; 63: 844855.

384 Oh SH, Patterson R. Surgery in corticosteroid-dependent asthmatics. J Allergy Clin Immunol 1974; 53: 345-351.

385 Bousquet J, Van Cauwenberge P, Khaltaev N. Allergic rhinitis and its impact on asthma. J Allergy Clin Immunol 2001; 108: Suppl. 5, S147-S334.

386 Allergic Rhinitis and its Impact on Asthma (ARIA). www.whiar.com Date last accessed: July 15, 2007.
387 Bernstein DI, Cohn JR. Guidelines for the diagnosis and evaluation of occupational immunologic lung disease: preface. J Allergy Clin Immunol 1989; 84: 791-793.

388 Bernstein IL, Chan-Yeung M, Malo JL, Bernstein DI. Definition and classification of asthma. In: Bernstein IL, Chan-Yeung M, Malo JL, Bernstein DI, eds. Asthma in the Workplace. New York, Marcel Dekker, 1999; pp. 1-4.

389 Chan-Yeung M, Desjardins A. Bronchial hyperresponsiveness and level of exposure in occupational asthma due to western red cedar (Thuja plicata). Serial observations before and after development of symptoms. Am Rev Respir Dis 1992; 146: 1606-1609.

390 Lin FJ, Dimich-Ward H, Chan-Yeung M. Longitudinal decline in lung function in patients with occupational asthma due to western red cedar. Occup Environ Med 1996; 53: 753-756.

391 Mapp CE, Corona PC, De Marzo N, Fabbri L. Persistent asthma due to isocyanates. A follow-up study of subjects with occupational asthma due to toluene diisocyanate (TDI). Am Rev Respir Dis 1988; 137: 1326-1329.

392 Fabbri LM, Danieli D, Crescioli S, et al. Fatal asthma in a subject sensitized to toluene diisocyanate. Am Rev Respir Dis 1988; 137: 1494-1498.

393 Malo JL. Compensation for occupational asthma in Quebec. Chest 1990; 98: Suppl. 5, 236S-239S.

394 British Occupational Health Research Foundation. www.bohrf.org.uk/downloads/asthevre.pdf Date last accessed: July 15, 2007.

395 Gern JE, Lemanske RF Jr. Infectious triggers of pediatric asthma. Pediatr Clin North Am 2003; 50, 555-575: vi.

396 Busse WW. The role of respiratory viruses in asthma. In: Holgate S, ed. Asthma: Physiology, Immunopharmcology and Treatment. London, Academic Press, 1993; pp. 345-352.

397 Kraft M. The role of bacterial infections in asthma. Clin Chest Med 2000; 21: 301-313.

398 Grunberg K, Sterk PJ. Rhinovirus infections: induction and modulation of airways inflammation in asthma. Clin Exp Allergy 1999; 29: Suppl. 2, 65S-73S.

399 Johnston SL. Viruses and asthma. Allergy 1998; 53: 922-932.

400 Harding SM. Acid reflux and asthma. Curr Opin Pulm Med 2003; 9: 42-45.

401 Sontag SJ. Why do the published data fail to clarify the relationship between gastroesophageal reflux and asthma? Am J Med 2000; 108: Suppl. 4A, 159S-169S.

402 Szczeklik A, Stevenson DD. Aspirin-induced asthma: advances in pathogenesis, diagnosis, and management. J Allergy Clin Immunol 2003; 111: 913-921.

403 Szczeklik A, Nizankowska E, Czerniawska-Mysik G, Sek S. Hydrocortisone and airflow impairment in aspirininduced asthma. J Allergy Clin Immunol 1985; 76: 530-536.

404 Drazen JM. Asthma therapy with agents preventing leukotriene synthesis or action. Proc Assoc Am Physicians 1999; 111: 547-559.

405 Stewart AW, Mitchell EA, Pearce N, Strachan DP, Weilandon SK. The relationship of per capita gross national product to the prevalence of symptoms of asthma and other atopic diseases in children (ISAAC). Int J Epidemiol 2001; 30: 173-179.

406 Higgins BG, Britton JR, Chinn S, Cooper S, Burney PG, Tattersfield AE. Comparison of bronchial reactivity and 
peak expiratory flow variability measurements for epidemiologic studies. Am Rev Respir Dis 1992; 145: 588-593.

407 National Asthma Council, Australia. www.nationalasthma.org.au Date last updated: November 6, 2007. Date last accessed: July 15, 2007.
408 Haahtela T, Tuomisto LE, Pietinalho A, et al. A 10 year asthma programme in Finland: major change for the better. Thorax 2006; 61: 663-670.

409 Global Alliance against Chronic Respiratory Diseases (GARD) www.who.int/respiratory/gard/en/ Date last updated: 2007. Date last accessed: July 15, 2007. 